\title{
Intermodal Humanitarian Logistics Using Unit Load Devices
}

\author{
Hasan Kavlak ${ }^{1} \cdot$ Mustafa Alp Ertem ${ }^{1} \cdot$ Benhür Satır $^{1}[$ \\ Received: 30 July 2020 / Accepted: 11 July 2021 / Published online: 15 September 2021 \\ (c) King Fahd University of Petroleum \& Minerals 2021
}

\begin{abstract}
Intermodal freight transportation facilitates today's global trade. The benefits of intermodal freight transportation have been studied and are more observable in commercial logistics; however, the potential benefits of humanitarian logistics have not been thoroughly investigated. This research aims to present a resilient transportation framework by modeling intermodal transportation utilizing interoperable loading devices during disaster responses. We developed an integer programming model based on a time-space network by considering route and vehicle availabilities that are allowed to change with time. We consider vehicles with varying capacities in three transportation modes (i.e., ground, maritime, and air). The contribution of this study is threefold: (1) Two compatible unit load devices are proposed for humanitarian logistics; (2) a mathematical model that includes integer variable representation for vehicle fleets in different transportation modes is developed; and (3) intermodal transportation is compared with single-mode transportation using a real-life dataset. Our main results are as follows: In terms of cost, intermodal transportation is effective when demand occurs in consecutive periods and response time is short. Inventory is held more in intermodal transportation when it is cost-effective to use transportation modes with large capacities. Thus, the benefits of the responsiveness of intermodal transportation outweigh the costs of mode interchange and inventory holding for sudden-onset disasters where quick responses are needed within a short time.
\end{abstract}

Keywords Intermodal freight transportation $\cdot$ Dynamic network flow $\cdot$ Disaster response $\cdot$ Integer programming $\cdot$ Network flexibility

\section{Introduction}

The COVID-19 pandemic showed humanity that no matter how far we are in our scientific achievements and technological advances, we do not have a sound solution to disasters. An event is considered to be a disaster by the Centre for Research on the Epidemiology of Disasters (CRED) when at least one of the following conditions occurs:

1. Ten or more people reported killed

2. Hundred or more people reported affected

3. Declaration of a state of emergency

Benhür Satır

benhur@cankaya.edu.tr

Hasan Kavlak

hkavlak@cankaya.edu.tr

Mustafa Alp Ertem

alpertem@cankaya.edu.tr

1 Department of Industrial Engineering, Çankaya University, Eskisehir Yolu 29 km, 06790 Etimesgut, Ankara, Turkey
4. Call for international assistance (CRED [1]).

COVID-19 has been the most devastating disaster over the past century since the Spanish flu (1918). Nevertheless, a global disaster was not required to invoke the work on reducing the impact of disasters altogether for humanity. Each year, we were reminded of an annual average of more than 62,000 deaths and 186 million people affected during the last 40 years (UNDRR [2]). Moreover, an annual average of more than $\$ 118$ billion (USD) in economic losses have been reported (UNDRR [2]).

These high figures of human and economic loss lead researchers to study disasters. The academic literature on disasters can be classified into four phases: mitigation, preparedness, response, and recovery phases (Altay and Green [3]). The mitigation and preparedness phases are pre-disaster phases, whereas the latter two are post-disaster. Strengthening infrastructure, public training in addition to legislative work are examples of actions during the pre-disaster phases. Search and rescue activities, provision of food and shelter, 
or rebuilding infrastructure are examples of actions during post-disaster phases.

This research pertains to the logistics operations during the response phase of sudden-onset disasters. Humanitarian logistics can be defined as an emergency form of its commercial counterpart "for the purpose of alleviating the suffering of vulnerable people" (Kopzcak and Thomas [4]). A disaster is an emergency that causes a shortage in the supply of several items. Relief items refer to products needed in a disaster area, such as food, water, medicine, blankets, and tents. Transportation of relief items to the disaster areas plays an essential role in saving human lives (Özkapıc1 et al. [5]). Moreover, almost $80 \%$ of all humanitarian responses are logistics activities (Van Wassanhove [6]). Thus, even a small improvement in the efficiency of logistics activities is important in the overall response performance.

Response performance is measured by whether or not enough relief items are promptly provided for beneficiaries. Thus, a flexible transportation system resilient to the impact of disasters is critical to the survivability of beneficiaries (Adams et al. [7]). Using single-mode transportation has a higher risk of interruption of services. Multimodal transportation provides a more flexible system as it inherently provides alternative options (Ponomarov and Holcomb [8]). It has been shown that the deprivation cost of having insufficient relief supplies increases exponentially with time (Holguin-Veras et al. [9]; Holguin-Veras et al. [10]). Quicker transportation with multiple transportation mode options will result in less suffering by reducing response times.

The aim of this research is to develop a mathematical model for Intermodal Freight Transportation (IFT) in humanitarian logistics. IFT, a particular form of multimodal transportation, is "a system of transport whereby two or more modes of transport are used to deliver the same loading unit or truck in an integrated manner, without loading or unloading, in a [door to door] transport chain" (UNESCAP [11]). In today's commercial logistics, containerization and intermodal freight transportation are prevalent, especially over longer distances. Global trade would not be as convenient or fast if products themselves were handled instead of handling via intermodal transportation units (e.g., standard steel freight containers). IFT provides quicker service by reducing mode interchange times, thus utilizing humanitarian logistics (Ertem et al. [12]). Nevertheless, academic work on intermodal freight transportation and humanitarian logistics is not yet established.

Several advantages of IFT can be listed for humanitarian logistics. Firstly, if part of a road is hit by a disaster and is damaged, it cannot be used or it can only be used with service interruptions and lower capacities. Road transportation is the most utilized transportation mode during disaster and non-disaster times (Ertem et al. [13]). With IFT, one can switch to another transportation mode (e.g., rail, air, or water) on the damaged part. This availability is used for undisrupted delivery of relief items to beneficiaries. Secondly, IFT can solve the inherent coordination challenges (Balçık et al. [14]) in humanitarian logistics. Each entity in IFT might operate different modes, whereas a single company would operate all modes in multimodal transportation (IFRC [15]). Therefore, IFT operates as a decentralized system. Decentralization is necessary for an international disaster relief operation where international non-governmental organizations (INGOs) may be allowed to operate only on specific transportation modes within a country. The local government may not allow INGOs to deliver relief supplies beyond international airports (EMDAT [16]).

In order to realize the advantages of IFT in humanitarian logistics, a piece of equipment that is interoperable in different transportation modes is required. IFT utilizes standard $20 \mathrm{ft}$. or $40 \mathrm{ft}$. steel freight containers for interoperability. These containers (e.g., boxes) are called intermodal transportation units (ITUs). During a relief operation, different transportation modes may require a different type of ITU, which may result in changing ITUs and handling each relief item during mode changes. To overcome this challenge and save time of handling operations, we propose using an intermediary package for relief products/kits, namely a unit load device (ULD). ULDs are commonly used in airline transportation (IATA [17]). Certain ULDs are suitable for use in humanitarian logistics. Specifications of two compatible ULD types are given in Fig. 1. We propose putting ULDs into ITUs and, in some cases, putting them directly into the vehicles (such as putting ULDs into an airplane). IFT can benefit from using different modes of transportation, thereby increasing resilience without wasting time on handling. Therefore, we hypothesize that the benefits from using IFT in humanitarian logistics are better realized when ULDs are exploited.

The main objective of this study is to develop a mathematical model for using IFT in humanitarian logistics and to measure the benefits of IFT over single-mode transportation in a number of scenarios. To the best of our knowledge, this is the first study presenting IFT modeling in humanitarian logistics using loading units (Ertem et al. [12]). The contribution of this study is threefold: (1) Two compatible unit

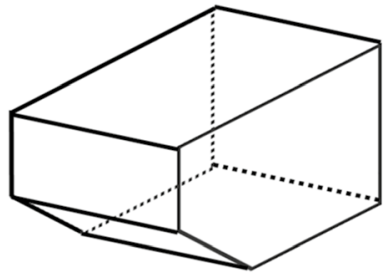

a) ULD-1 (AKE)

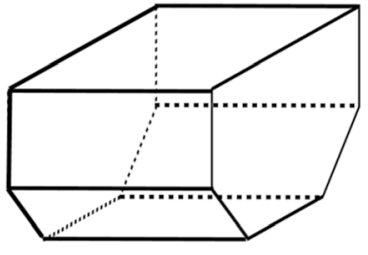

b) ULD-2 (AKH)
Fig. 1 ULD types 
load devices are proposed for humanitarian logistics; (2) a mathematical model which includes integer variable representation for vehicle fleets on different transportation modes is developed; and (3) intermodal transportation is compared with single-mode transportation using a real-life dataset.

The remainder of this paper is organized as follows: In the following section, we explain our research methodology. In Sect. 3, we present the motivation of our study and the literature gap. In Sect. 4, we present a description of the problem framework and the mathematical model we propose. In Sect. 5, we test our mathematical model using various scenarios and discuss our findings. In Sect. 6, we provide an extension of our mathematical model and test the resilience and flexibility of IFT in terms of satisfaction of demand and mode availability. Finally, we draw conclusions, note the limitations of our study, and suggest future research directions in Sect. 7.

\section{Research Methodology}

Our research methodology is composed of seven steps, as shown in Fig. 2. We first identify the literature gap based on Ertem et al. [12]. Then, we investigate the features of commercial intermodal transportation that might be utilized in

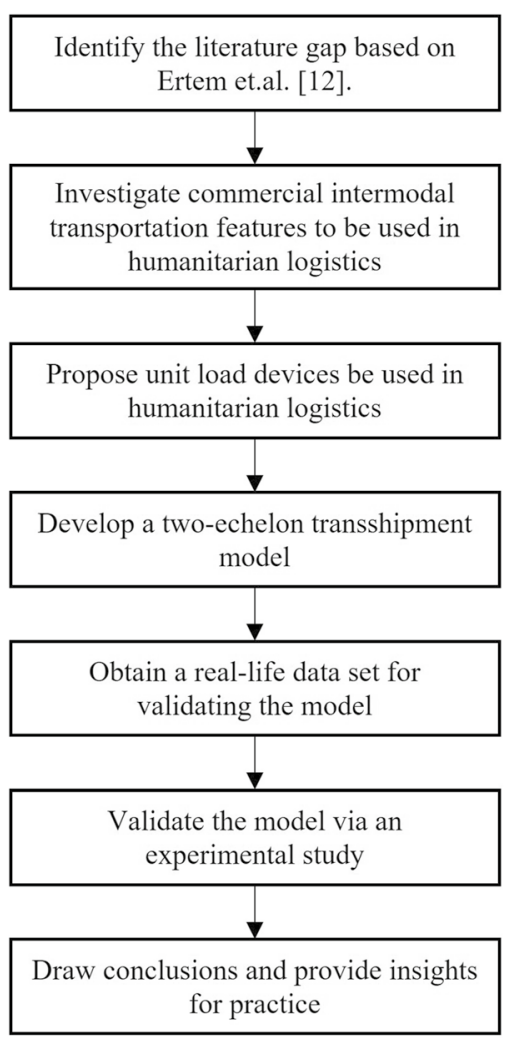

Fig. 2 Research methodology steps humanitarian logistics. As a result of this investigation, we propose unit load devices that are suitable for use in humanitarian logistics. The fourth step includes the development of a two-echelon mathematical model for intermodal transportation of relief supplies. Later, we gather a real-life dataset to be used in our experimental study. We draw conclusions and provide insights for practice after completing a scenariobased experimental study.

\section{Literature Review}

This research is motivated by two recent literature surveys: Özdamar and Ertem [18] and Ertem et al. [12]. Özdamar and Ertem [18] reviewed the mathematical models in humanitarian logistics for the two post-disaster phases: response and recovery. The response phase includes mass evacuation, road clearing, relief, and transportation of casualties. The recovery phase includes debris collection, sustaining relief operations after an initial emergency period, and reconstructing any disrupted elements of beneficiaries' lives (Özdamar and Ertem [18]). Their survey categorized the models in terms of their network flow (e.g., dynamic network flow (DNF) and static network flow (SNF)), and vehicle representation styles (e.g., integer variables and binary variables).

There are studies considering a single-mode under a multi-echelon setting in the humanitarian logistics literature. For example, Tavana et al. [19] planned both pre- and post-disaster phases considering location, inventory control, and routing decisions under a multi-echelon network setting for perishable items. They used a multi-objective mixedinteger linear programming model. Here, we concentrate on the literature considering the use of multiple transportation modes. Ertem et al. [12] presented a comprehensive literature and practitioner review dedicated to IFT in humanitarian logistics. They discussed how only 13 out of 369 academic articles mentioned transportation mode changes during disaster relief operations. They also indicated that none of these articles specifically discussed transportation using ITUs or ULDs. Table 1 summarizes thirteen articles that report transportation with multiple modes along with the contribution of this work.

It can be concluded from Table 1 that only seven articles include a transportation mode change feature. Among those seven articles, there is no study which combines multi-commodity multi-period intermodal transportation using ITUs and ULDs while minimizing cost.

We further investigate the most related studies reported in Table 1 that follow a similar problem structure with the classification in our study. In Table 2, our study is compared with the three most related studies in the literature according to the model and solution, where the model includes sets, 
Table 1 Analysis of studies involving multimodal transportation (Ertem et al. [13]) and a comparison with our study

\begin{tabular}{|c|c|c|c|c|c|c|c|c|}
\hline Short Name & Model & Method & $\begin{array}{l}\text { Trans- } \\
\text { shipment } \\
\text { point }\end{array}$ & Objective & $\begin{array}{l}\text { Multi- } \\
\text { commodity } \\
\text { transportation }\end{array}$ & $\begin{array}{l}\text { First transpor- } \\
\text { tation mode }\end{array}$ & $\begin{array}{l}\text { Second } \\
\text { transportation } \\
\text { mode }\end{array}$ & Disaster type \\
\hline $\begin{array}{c}\text { Abdelgawad and } \\
\text { Abdulhai [51] }\end{array}$ & Evacuation & $\begin{array}{l}\text { Linear pro- } \\
\text { gramming, } \\
\text { mixed-inte- } \\
\text { ger program- } \\
\text { ming }\end{array}$ & No & $\begin{array}{l}\text { Min. cost } \\
\text { Min. waiting } \\
\text { time }\end{array}$ & No & Road & Rail & Not mentioned \\
\hline $\begin{array}{l}\text { Adivar and Mert } \\
\text { [52] }\end{array}$ & $\begin{array}{l}\text { Relief supplies } \\
\text { routing }\end{array}$ & $\begin{array}{l}\text { Linear pro- } \\
\text { gramming }\end{array}$ & Yes & $\begin{array}{l}\text { Min. cost } \\
\text { Max. cred- } \\
\text { ibility }\end{array}$ & Yes & Not mentioned & $\begin{array}{l}\text { Not men- } \\
\text { tioned }\end{array}$ & Flood \\
\hline $\begin{array}{l}\text { Barbarosoğlu } \\
\text { and Arda [53] }\end{array}$ & $\begin{array}{l}\text { Relief supplies } \\
\text { routing }\end{array}$ & $\begin{array}{l}\text { Stochastic } \\
\text { program- } \\
\text { ming }\end{array}$ & Yes & Min. cost & Yes & Air & Road & Earthquake \\
\hline $\begin{array}{l}\text { Clark and } \\
\text { Culkin [22] }\end{array}$ & $\begin{array}{l}\text { Relief supplies } \\
\text { routing }\end{array}$ & $\begin{array}{l}\text { Mixed-integer } \\
\text { program- } \\
\text { ming }\end{array}$ & No & Min. cost & Yes & Air & Road, rail, sea & Earthquake \\
\hline $\begin{array}{l}\text { Haghani and Oh } \\
\text { [20] }\end{array}$ & $\begin{array}{l}\text { Relief supplies } \\
\text { routing }\end{array}$ & Heuristic & Yes & Min. cost & Yes & Not mentioned & $\begin{array}{l}\text { Not men- } \\
\text { tioned }\end{array}$ & All \\
\hline $\begin{array}{l}\text { Haghani and Oh } \\
\text { [54] }\end{array}$ & $\begin{array}{l}\text { Relief supplies } \\
\text { routing }\end{array}$ & $\begin{array}{l}\text { Mixed-integer } \\
\text { program- } \\
\text { ming }\end{array}$ & Yes & Min. cost & Yes & Not mentioned & $\begin{array}{l}\text { Not men- } \\
\text { tioned }\end{array}$ & All \\
\hline $\mathrm{Hu}[55]$ & $\begin{array}{l}\text { Relief supplies } \\
\text { routing }\end{array}$ & $\begin{array}{l}\text { Mixed-integer } \\
\text { program- } \\
\text { ming }\end{array}$ & Yes & Min. cost & No & Road & Rail, sea & Not mentioned \\
\hline $\begin{array}{l}\text { Özdamar et al. } \\
\text { [21] }\end{array}$ & $\begin{array}{l}\text { Relief supplies } \\
\text { routing }\end{array}$ & $\begin{array}{l}\text { Linear pro- } \\
\text { gramming, } \\
\text { mixed-inte- } \\
\text { ger program- } \\
\text { ming }\end{array}$ & Yes & Max. delivery & Yes & Air & Road, rail, sea & $\begin{array}{l}\text { Natural disas- } \\
\text { ters }\end{array}$ \\
\hline $\begin{array}{l}\text { Salmerón and } \\
\text { Apte [56] }\end{array}$ & $\begin{array}{l}\text { Relief supplies } \\
\text { routing } \\
\text { Evacuation }\end{array}$ & $\begin{array}{l}\text { Stochastic } \\
\text { program- } \\
\text { ming, } \\
\text { mixed-inte- } \\
\text { ger program- } \\
\text { ming } \\
\text { Stochastic } \\
\text { program- } \\
\text { ming, } \\
\text { mixed-inte- } \\
\text { ger program- } \\
\text { ming }\end{array}$ & No & $\begin{array}{l}\text { Min. expected } \\
\text { casualties } \\
\text { Min. expected } \\
\text { unmet } \\
\text { transfer } \\
\text { population }\end{array}$ & No & Air & Road & Not mentioned \\
\hline Tean [57] & $\begin{array}{l}\text { Relief supplies } \\
\text { routing }\end{array}$ & Simulation & No & $\begin{array}{l}\text { Max. survival } \\
\text { rate }\end{array}$ & No & Air & Road, rail, sea & $\begin{array}{c}\text { Earthquake, } \\
\text { hurricane }\end{array}$ \\
\hline $\begin{array}{l}\text { Vitori- } \\
\text { ano et al. [58] }\end{array}$ & $\begin{array}{l}\text { Relief supplies } \\
\text { routing }\end{array}$ & $\begin{array}{l}\text { Goal program- } \\
\text { ming }\end{array}$ & Yes & $\begin{array}{l}\text { Min. cost } \\
\text { Max. min reli- } \\
\text { ability }\end{array}$ & No & Air & Road, rail, sea & Food crisis \\
\hline $\begin{array}{l}\text { Yi and Kumar } \\
\text { [59] }\end{array}$ & $\begin{array}{l}\text { Relief supplies } \\
\text { routing } \\
\text { evacuation }\end{array}$ & $\begin{array}{l}\text { Mixed-integer } \\
\text { program- } \\
\text { ming }\end{array}$ & No & $\begin{array}{l}\text { Min. service } \\
\text { delay }\end{array}$ & Yes & Road & $\begin{array}{l}\text { Not men- } \\
\text { tioned }\end{array}$ & All \\
\hline Zhu et al. [60] & $\begin{array}{l}\text { Relief supplies } \\
\text { routing }\end{array}$ & $\begin{array}{l}\text { Integer pro- } \\
\text { gramming }\end{array}$ & No & Min. cost & Yes & Road & Rail & $\begin{array}{l}\text { Earthquake, } \\
\text { flood, } \\
\text { typhoon }\end{array}$ \\
\hline Our study & $\begin{array}{l}\text { Relief supplies } \\
\text { routing }\end{array}$ & $\begin{array}{l}\text { Integer pro- } \\
\text { gramming }\end{array}$ & Yes & Min. cost & Yes & Road & Rail, sea, air & Sudden onset \\
\hline
\end{tabular}




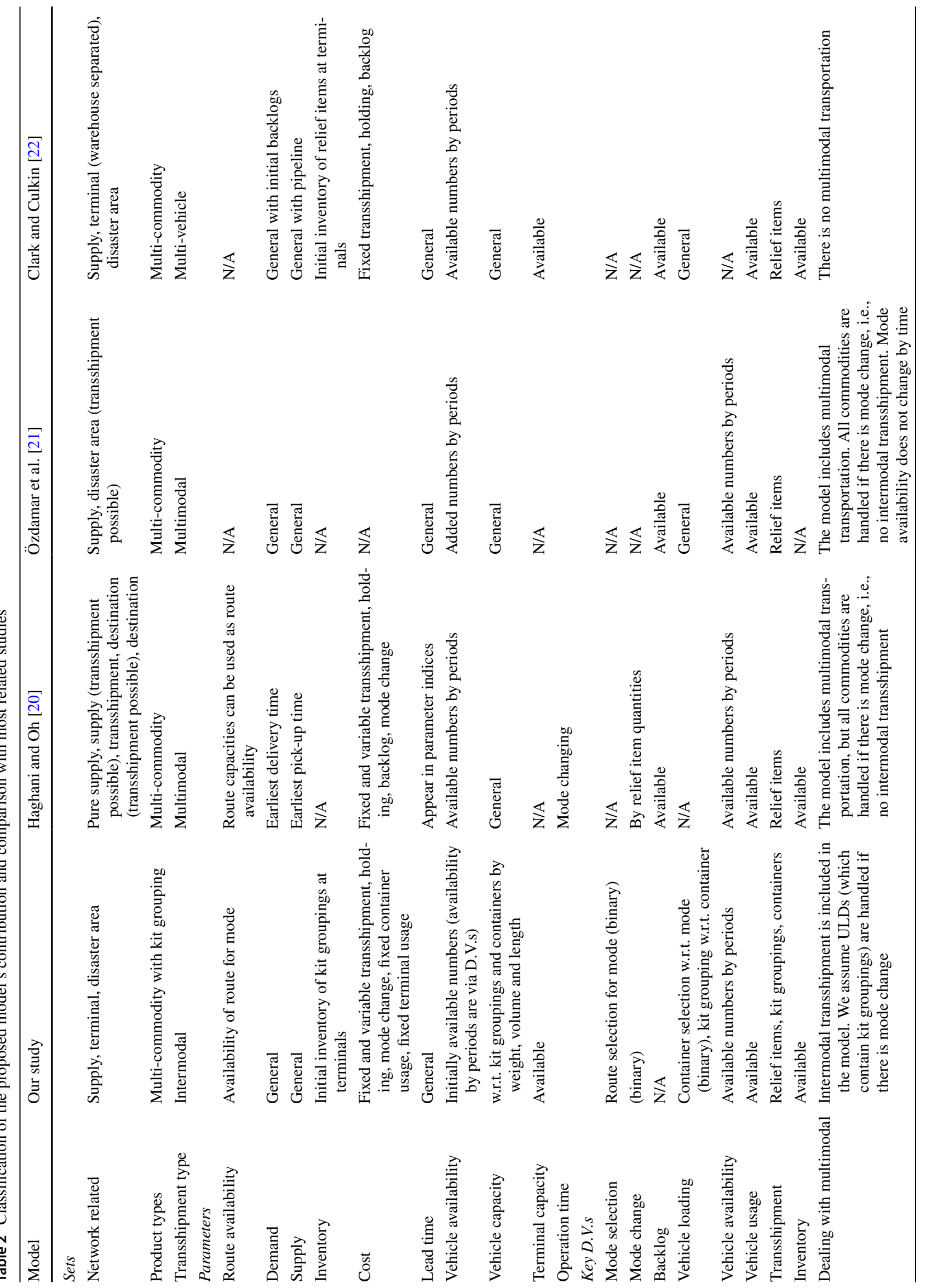

I Springer 
parameters, key decision variables, dealing with multimodal property, constraints, and objective(s).

To be concise, we highlight several improvements and a limitation of our approach. The only study considering intermodal transshipment is ours. The effects of intermodality are seen in sets (transshipment type), key decision variables (mode transshipment), and while dealing with multimodality. In line with intermodality, we assume kit groupings, which also does not appear in the other three studies. We considered vehicle availability w.r.t. periods (vehicle availability in parameters and vehicle availability in key decision variables). Haghani and Oh [20] and Özdamar et al. [21] also considered the decision variable of vehicle availability w.r.t. periods; however, they did not specifically keep track of vehicles. Instead, they assumed an available (all or newly added) number of vehicles for periods as a parameter. Route availability is another significant difference in our study (route availability in parameters).

We model the route availability w.r.t. the transshipment mode and period and define it by binary parameters. Haghani and Oh [20] used mode capacities which can also define availability, while the other two studies did not consider route availability. Özdamar et al. [21] assumed mode availability, which does not change over time, but in turn defines a mode on a route that is either available or not available throughout the planning horizon.

Mode selection and change are the other two significant differences in our study. Özdamar et al. [21] used integer decision variables and imposed mode selection via a connection to a dummy node, which is not equivalent to using a decision variable for mode selection. We used a binary decision variable for mode change. Haghani and Oh [20] used a decision variable defining the number of relief items that change modes, and the other two studies did not consider mode changes. Only Clark and Culkin [22] used an exact solution algorithm, like us. Backlogs are assumed in the other three studies; however, we did not allow backlogs in our main model.

When Table 2 is examined, intermodality, parking limitations (e.g., container capacity of a warehouse), and minimizing holding costs are our novel contributions to the literature. In order to ensure intermodality, ITU and ULD are defined for humanitarian logistics. Moreover, capacity is defined for these transportation units. Transportation capacities of suppliers and warehouses are altered dynamically during each period to account for vehicle availability. Therefore, the proposed model has dynamic capacitated suppliers and warehouses.

According to the classification of Özdamar and Ertem [18], a DNF-TS model is developed here to minimize transportation, operation, and inventory holding costs considering the availability of capacitated vehicles, routes and depots, and multiple transportation modes for multipleperiods. Moreover, vehicles are represented as integer flows. Although Haghani and Oh [20], Özdamar et al. [21], and 
Clark and Culkin [22] mentioned multiple transportation modes, they did not specifically discuss IFT or ULDs.

Therefore, the proposed model here is unique in the literature and a contribution to addressing the literature gap at the intersection of intermodal freight transportation and humanitarian logistics research topics.

\section{The Model}

\subsection{Problem Description}

The flow of relief items starting with acquisition from suppliers through the delivery to disaster areas is given in Fig. 3. We assume that the total number of relief-items of any type required per capita is known a priori. This is our first assumption, abbreviated as A\#1. Then, one can define a combination of items needed for a group of people, which can be called a "kit." Vaillancourt [23] emphasized the importance of kit management, which includes kit design. In our study, we assume one type of kit and consider kit management steps beyond the scope of our study (A\#2). For example, a group of five people may need one tent, five pillows, and ten blankets, which forms a shelter kit. We use shelter kits as a unit for transportation. These shelter kits are put into large boxes (e.g., $40 \mathrm{ft}$. steel freight containers, swap bodies, semi-trailers), which corresponds to ULDs or ITUs in our study (IFRC [15]).

Referring back to Fig. 3, we assume that the flow is only downstream; i.e., there is no transportation within the same level (Baskaya et al. [24]) or upstream in the multi-echelon network (A\#3). Items are first grouped as kits (ULDs) at the supplier locations. We assume that each supplier can provide every type of item without any quantity capacity (A\#4). Although unlimited supply assumption may seem unrealistic, items of consideration are commodities that can be easily found from other suppliers. To highlight the contribution of IFT, suppliers only differ in their availability of transportation modes.

Different types of ULD are used in practice. We allowed the two most common types of ULD in our study. All ULDs are loaded into ITUs and then transferred to terminals (i.e., hubs, and transfer and storage locations). Depending on the transportation mode to be used from then on, ITUs may be directly transferred to disaster areas or disaggregated to ULDs to load into aircraft or to stock. Terminals are the unique storage locations where a ULD is the only medium that can be used to stock relief items for future use. When ULDs or ITUs arrive in a disaster area, they must be disaggregated down to relief items in order to be distributed to beneficiaries. In our model, we assume an unlimited availability of ULDs and ITUs (A\#5) and demand is in terms of kits (ULDs) so that we do not explicitly consider the final disaggregation and distribution (A\#6) and consider lastmile distribution (Balçık et al. [25]) beyond the scope of our study.

In our study, we assume a two-echelon transshipment network (A\#7), which is used in Turkey by the Disaster and Emergency Management Presidency (DEMP). Suppliers are responsible for transportation from suppliers to terminals, and terminals are responsible for transportation from terminals to disaster areas. We assume that suppliers and terminals can use only their vehicles which return to their original locations after transportation has been accomplished (A\#8). We aim to represent the decentralization in humanitarian responses with this enforcement (Balçık et al. [14]). We assume three transportation modes, namely ground, maritime, and air (A\#9). Trucks and trains operate in ground mode on separate sub-networks, ships are used for maritime transportation, and helicopters and
Fig. 3 Transportation of relief items with ULD

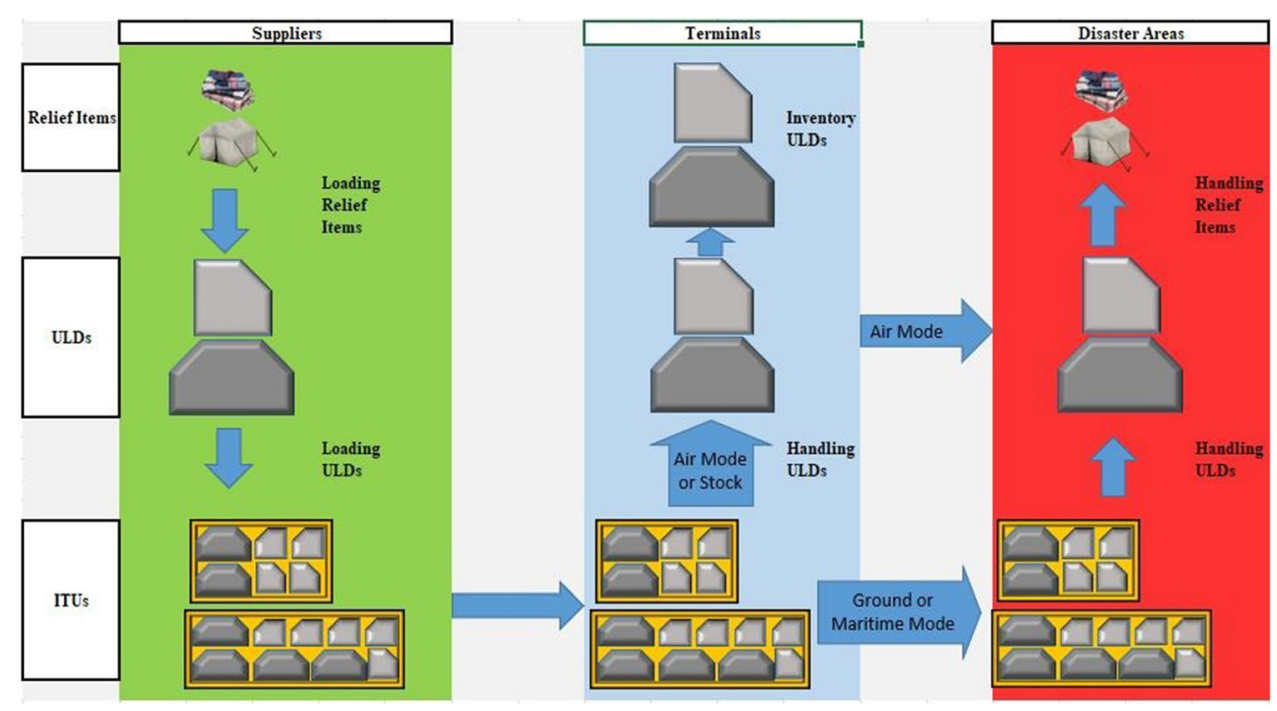


air freighters move in air mode, and they can share their sub-networks when necessary. We assume a limited number of vehicles to operate in each transportation mode at the beginning of the response phase (A\#10). Suppliers send relief items to terminals at critical hub locations, and then, the items are shipped to disaster areas. We assume that terminals can hold inventory w.r.t. their capacity, but disaster areas cannot (A\#11). This structure is used by DEMP.

After a disaster occurs, the feasibility of transportation is affected, and this effect is unpredictable. Moreover, vehicle availabilities w.r.t. time have to be considered. Terminal capacities may also change. Thus, capacities and availabilities will change as time progresses. To overcome these uncertainties inherent to the problem, we constructed a dynamic model that incorporated dynamic vehicle availabilities, delivery path availabilities, vehicle capacities, depot capacities, the lead time of vehicles, the number of relief items, and different transportation modes.

For ULDs, we assumed flow conservation and force equality in inventory balance constraints (A\#12). Therefore, we would assume non-perishability of relief items, which is valid for shelter kits consisting of a tent, blankets, and pillows.

Considering the standard dimensions of ULDs (IATA [17]) and ITUs, we use the AKE type of ULD as ULD-1, the AKH type of ULD as ULD-2 (see Fig. 1), and the $40 \mathrm{ft}$. standard steel freight container (with internal dimensions of $12.035 \mathrm{~m} \times 2.352 \mathrm{~m} \times 2.391 \mathrm{~m}$ ) as the ITU in our study. Then, we calculated the number of ULDs to be loaded into the ITU (or vehicle in direct loading). Although the maximum number of ULDs that can fit into an ITU has not been tested in a disaster operation, we assume that our numbers are valid since we simply use the volumes (A\#13).

We assumed that the total demand is deterministic as we are using demand instances from previous earthquakes (A\#14). We also assumed that demand does not arise at all at the time of disaster (i.e., period zero) as a whole, but is distributed over time with the following attributes (A\#15). Demand has a response period (the period that the first demand realization occurs after the disaster), a density (total demand is realized in a "density" number of periods in equal amounts), and an interval distribution (number of periods in consecutive demand occurrences). All disasters occur once at a time and consequences are immediate (aftershock

$M O_{i j m t}=\left\{\begin{array}{l}1, \text { if transportation mode } m \text { is used to transport items from supplier } i \text { to terminal } j \text { at start of time } t \\ 0, \text { otherwise }\end{array}\right.$

$N_{j k m t}=\left\{\begin{array}{l}1, \text { if transportation mode } m \text { is used to transport items from terminal } j \text { to disaster area } k \text { at start of time } t \\ 0, \text { otherwise }\end{array}\right.$

earthquakes may be an exception, but the main destruction is with the very first earthquake), but the total demand is not clear since communication with beneficiaries is not possible. Those responsible/personnel need time to arrive at the location of a disaster, and time is required to calculate or estimate demand. Therefore, despite total demand being created at the time of disaster (time zero), realization of demand is distributed over time. We assume all demands should be met on time (A\#16) for our main model. We further relax this assumption as an extension of our model in Sect. 6.

For comparison purposes, we developed a single-mode transportation model in which we limited intermodality. We assumed any mode among available modes could be selected, but only that single mode was to be used in transportation (A\#17).

\subsection{Mathematical Model}

Different objectives and factors are considered for humanitarian logistics, such as minimization of waiting time, casualties, the number of vehicles, unmet demand or maximization of delivery, served beneficiaries, and survival rates. As can be seen in Özdamar and Ertem [18], (Tables 1, 2), many studies consider minimization of costs as the objective function. Cost may be composed of all the objectives above (e.g., penalizing waiting time or unmet demand) plus transportation-related costs (all types of personnel, transportation of items/mediums, personnel/time/energy for handling, fuel for vehicles, maintenance/rent of vehicles), facility/equipment usage costs (e.g., terminal/warehouse usage rent/depreciation, equipment or container usage/fixed purchases), opportunity costs (e.g., inventory holding), or other costs. Since cost is the broadest objective that might cover any undesired or desired situation, we prefer using cost as the objective function in our model. We assume all demand is met, and consequently, we do not include unmet demand penalty costs in our model, which allows us to focus primarily on the benefits of using intermodal transportation. For the problem described in Sect. 4.1, we propose an Intermodal Humanitarian Logistics Mathematical Model (IMM) to minimize cost. The index sets and parameters are given in Appendix A, and the decision variables are presented below.

\subsubsection{Decision Variables}


$W_{j t}=\left\{\begin{array}{l}1, \text { if terminal } j \text { is used in time } t \\ 0, \text { otherwise }\end{array}\right.$
$V_{m i t}=$ Number of available vehicle in mode $m$ in supplier $i$ at start of time $t$

$V U_{i j m t}=$ Number of vehicle in mode $m$ used from supplier $i$ to terminal $j$ at start of time $t$

$V E U_{j k m t}=$ Number of available vehicle in mode $m$ used from terminal $j$ to disaster area $k$ at start of time $t$

$X_{\text {hijm }}=$ Amount of item $h$ transported by transportation mode $m$ from supplier $i$ to terminal $j$ at start of time $t$

$Y_{h j k m t}=$ Amount of item $h$ transported by transportation mode $m$ from terminal $j$ to disaster area $k$ at start of time $t$

$S U L D_{\text {rcijmt }}=$ Number of ULD $r$ in ITU $c$ transported by ransportation mode $m$ from supplier $i$ to terminal $j$ at start of time $t$

$W U L D_{r c j k m t}=$ Number of ULD $r$ in ITU $c$ transported by transportation mode $m$ from terminal $j$ to disaster area $k$ at start of time $t$

$S I T U_{c i j m t}=$ Number of ITU $c$ transported by transportation mode $m$ from supplier $i$ to terminal $j$ at start of time $t$

$W I T U_{c j k m t}=$ Number of ITU $c$ transported by transportation mode $m$ from terminal $j$ to, disaster area $k$ at start of time $t$

$I T U S_{c i j m t}=\left\{\begin{array}{l}1, \text { if ITU } c \text { is transported from supplier } i \text { to terminal } j \text { by transportation mode } m \text { at start of time } t \\ 0, \text { otherwise }\end{array}\right.$

$I T U W_{c j k m t}= \begin{cases}1, & \text { if ITU } c \text { is transported from terminal } j \text { to disaster area } k \text { by transportation mode } m \text { at start of time } t \\ 0, & \text { otherwise }\end{cases}$

$I N_{r j t}=$ Inventory of ULD $r$ in terminal $j$ left over at the end of time $t$

type usage, and total inventory holding over all periods (1). These costs are composed of several cost items,

$M C_{j m m^{\prime} t}=\left\{\begin{array}{ll}1, & \text { if there is a mode changing between transportation mode } m \text { of supplier } i \text { and transportation mode } m^{\prime} \text { of terminal } j \text { at start of time } t \\ 0, & \text { otherwise }\end{array}\right\}$.

such as cost of fuel for vehicles, the maintenance costs of vehicles and equipment, cost of personnel who handle and operate vehicles, depreciation cost of vehicles and equipment, handling costs of loading/unloading of vehicles or transportation units, mode changes between 
vehicles or transportation units, terminal rent, costs of acceptance activities, the examination of supply items, weighing, extra storage charges for waiting areas, customs clearance charges, and leashing/unleashing costs.

$$
\begin{aligned}
& \text { Minimize } \sum_{m=M}^{M} \sum_{j \in W H} \sum_{i \in S} \sum_{r \in U L D} \sum_{c \in I T U} \sum_{t \in T I M} c_{r i j m} \text { weuld }_{r} S U L D_{r c i j m t} \\
& +\sum_{m=M}^{M} \sum_{k \in D A} \sum_{j \in W H} \sum_{r \in U L D} \sum_{c \in I T U} \sum_{t \in T I M} \text { co }_{r j k m} \text { weuld }_{r} W U L D_{r c j k m t} \\
& +\sum_{t \in T I M} \sum_{j \in W H} \sum_{r \in U L D} h o_{r j t} I N_{r j t}+\sum_{j \in W H} \sum_{t \in T I M} f c i h l W_{j t} \\
& +\sum_{j \in W H} \sum_{m \in T M} \sum_{m^{\prime} \in T M} \sum_{t \in T I M} m c c_{j m m \prime} M C_{j m m / t} \\
& +\sum_{i \in S} \sum_{j \in W H} \sum_{m \in T M} \sum_{t \in T I M} f c v_{m} V U_{i j m t}+ \\
& +\sum_{j \in W H} \sum_{k \in D A} \sum_{m \in T M} \sum_{t \in T I M} f c v_{m} V E U_{j k m t} \\
& +\sum_{m=1}^{M-2} \sum_{k \in D A} \sum_{j \in W H} \sum_{c \in I T U} c c o_{c j k m} W I T U_{c j k m t} \\
& +\sum_{m=1}^{M-2} \sum_{i \in S} \sum_{j \in W H} \sum_{c \in I T U} \sum_{t \in T I M} c c_{c i j m} S I T U_{c i j m t} \\
& +\sum_{m=1}^{M} \sum_{k \in D A} \sum_{j \in W H} \sum_{c \in I T U} \sum_{t \in T I M} f_{c i t u} I T U W_{c j k m t} \\
& +\sum_{m=1}^{M} \sum_{i \in S} \sum_{j \in W H} \sum_{c \in I T U} \sum_{t \in T I M} f_{c i t u_{c}} I T U S_{\text {cijmt }}
\end{aligned}
$$

\section{Demand Constraints}

2. Relief item demand of each disaster area is satisfied in each period (2).

3. Item flows are converted to ULD flows from suppliers to terminals (3).

4. Item flows are converted to ULD flows from terminals to disaster areas (4).

$\sum_{m=1}^{M} \sum_{j=1}^{J} Y_{h j k m\left(t-l_{j k m}\right)} \geq d e_{h k t} \quad \forall h \in I T, \quad \forall k \in D A, \forall t \in T I M$

\section{ITU Capacity of Vehicles}

5. The number of ITUs transported from a supplier to a terminal can be at most the total ITU capacity of vehicles in a transportation mode used for the selected path (5).

6. The number of ITUs transported from a terminal to disaster areas can be at most the total ITU capacity of vehicles in a transportation mode used for the selected path (6).

$$
\begin{gathered}
S I T U_{c i j m t} \leq c a_{c m} V U_{i j m t} \quad \forall c \in I T U, \forall i \in S, \\
\forall j \in W H, \forall m \in T M, \forall t \in T I M \\
W I T U_{c j k m t} \leq c a_{c k} V E U_{j k m t} \quad \forall c \in I T U, \forall k \in D A, \\
\forall j \in W H, \forall m \in T M, \forall t \in T I M .
\end{gathered}
$$

\section{ULD and ITU Flow from Suppliers to Terminals}

7. The total length of ULDs loaded has to be at least the total length of the ITUs transported by the vehicle (7). Note that the height of the ULDs and ITUs is constant and they do not put a constraint on loading.

8. If the ITU type is not selected for the route and transportation mode, the number of ITUs transported by the transportation mode throughout should be zero (8).

9. If the number of ITUs transported by the transportation mode throughout is zero, a binary variable indicating ITU type selected for the route and the transportation mode has to be zero (9).

10. The ITU type can be assigned to one route for each transportation mode and period (10).

11. If the route is not assigned with a transportation mode, the ITU type cannot be assigned (11).

$$
\begin{aligned}
& \sum_{r \in U L D} \text { leuld }_{r} S U L D_{\text {rcijmt }} \leq \text { leitu }_{c} S I T U_{\text {cijmt }} \\
& \forall c \in I T U, \forall i \in S, \forall j \in W H, \forall m \in T M, \forall t \in T I M
\end{aligned}
$$

$$
\begin{aligned}
& X_{h i j m t}=\sum_{c \in I T U} \sum_{r \in U L D} i_{h r} S U L D_{r c i j m t} \quad \forall h \in I T, \forall i \in S, \forall j \in W H, \forall m \in T M, \forall t \in T I M \\
& Y_{h j k m t}=\sum_{c \in I T U} \sum_{r \in U L D} i_{h} g_{h r} W U L D_{r c j k m t} \quad \forall h \in I T, \forall j \in W H, \forall k \in D A, \forall m \in T M, \forall t \in T I M
\end{aligned}
$$


$S I T U_{\text {cijmt }} \leq q I T U S_{\text {cijmt }} \quad \forall c \in I T U, \forall i \in S$,

$\forall j \in W H, \forall m \in T M, \forall t \in T I M$

$I T U S_{c i j m t} \leq S I T U_{\text {cijmt }} \quad \forall c \in I T U, \forall i \in S$,

$\forall j \in W H, \forall m \in T M, \forall t \in T I M$

$\sum_{j \in W H} \sum_{i \in S} \sum_{c \in I T U} I T U S_{c i j m t} \leq 1 \quad \forall m \in T M, \forall t \in T I M$

$\sum_{c \in I T U} I T U S_{c i j m t} \leq M O_{i j m t} \quad \forall i \in S, \forall j \in W H, \forall m \in T M, \forall t \in T I M$.

\section{ULD and ITU Flow from Terminals to Disaster Areas}

12. Constraint Set (12) works similarly to Constraint Set (7) for ULD and ITU operations from terminals to disaster areas.

13. Constraint Set (13) works similarly to Constraint Set (8) for ULD and ITU operations from terminals to disaster areas.

14. Constraint Set (14) works similarly to Constraint Set (9) for ULD and ITU operations from terminals to disaster areas.

15. Constraint Set (15) works similarly to Constraint Set (10) for ULD and ITU operations from terminals to disaster areas.

16. Constraint Set (16) works similarly to Constraint Set (11) for ULD and ITU operations from terminals to disaster areas.

$\sum_{r \in U L D}$ leuld $_{r} W U L D_{r c j k m t} \leq$ leitu $_{c} W_{\text {ITU }} U_{c j k m t} \quad \forall c \in I T U, \forall k \in D A, \forall j \in W H, \forall m \in T M, \forall t \in T I M$

$W I T U_{c j k m t} \leq q I T U W_{c j k m t} \quad \forall c \in I T U, \forall k \in D A, \forall j \in W H, \forall m \in T M, \forall t \in T I M$

$I T U W_{c j k m t} \leq W I T U_{c j k m t} \quad \forall c \in I T U, \forall m \in D A, \forall j \in W H, \forall k \in T M, \forall t \in T I M$

17. Total ending ULD inventory of the previous period and total ULDs received from the supplier (i.e., those having departed from the supplier some lead time ago) cannot exceed the ULD capacity of the terminal (17).

18. The total ITUs received from a supplier cannot exceed the ITU capacity of the terminal (18).

$$
\begin{aligned}
& \sum_{m \in T M} \sum_{i \in S} \sum_{c \in I T U} \sum_{r \in U L D} S U L D_{r c t i j m}\left(t-l t_{i j m}\right) \\
& +\sum_{r \in U L D} I N_{r j t-1} \leq \text { cwuld }_{j} W_{j t} \quad \forall j \in W H, \forall t \in T I M
\end{aligned}
$$

$\sum_{m \in T M} \sum_{i \in S} \sum_{c \in I T U} \operatorname{SITU} U_{c i j m\left(t-l t_{i j m}\right)} \leq c w i t u_{j} W_{j t} \quad \forall j \in W H, \forall t \in T I M$

\section{Mode Selection According to Availability of Routes}

19. Mode selection can be made from the supplier to the terminal if the mode is available (19).

20. Mode selection can be made from the terminal to the disaster if the mode is available (20).

$M O_{i j m t} \leq a_{i j m t} \quad \forall i \in S, \forall j \in W H, \forall m \in T M, \forall t \in T I M$

$N_{i j m t} \leq a v_{j k m t} \quad \forall j \in W H, \forall k \in D A, \forall m \in T M, \forall t \in T I M$.

\section{ULD Inventory Balance Equation for Terminals}

21. Inventory balance constraints for the terminals after the first period are given in (21).

22. Inventory balance constraints for the terminals for the first period are given in (22).

$$
\begin{gathered}
\sum_{j \in W H} \sum_{k \in D A} \sum_{c \in I T U} I T U W_{c j k m t} \leq 1 \quad \forall m \in T M, \forall t \in T I M \\
\sum_{c \in I T U} I T U W_{c j k m t} \leq N_{j k m t} \quad \forall k \in D A, \forall j \in W H, \forall m \in T M, \forall t \in T I M
\end{gathered}
$$

\section{Terminal Capacity}




\section{Vehicle Flow Balance Equation and Vehicle Assignment}

23. The number of available vehicles at the suppliers for the first period is calculated by considering the initial availability (23).

24. The number of available vehicles at the suppliers for the second period is calculated by considering the usage of the previous period (24).

25. The number of available vehicles at the suppliers for and after the third period is calculated by considering the arrival of vehicles completing their tours (25).

26. The number of available vehicles at the suppliers is limited by the total number of vehicles owned (26).

27. The number of vehicles used at the suppliers by a transportation mode can be at most the number of available vehicles (27).

28. Suppliers cannot use vehicles in a transportation mode if the same mode is not assigned to a route from the suppliers to the terminals (28).

29. The number of available vehicles at the terminals for the first period is calculated by considering initial availability (29).

30. The number of available vehicles at the terminals for the second period is calculated by considering the usage of the previous period (30).

31. The number of available vehicles at the terminals for and after the third period is calculated by considering the arrival of the vehicles completing their tours (31).

32. The number of available vehicles at the terminals is limited by the total number of vehicles owned (32).

33. The number of vehicles used at the terminals in a transportation mode can be at most the number of available vehicles (33).

34. Terminals cannot use vehicles in a transportation mode if the same mode is not assigned to a route from the terminals to the disaster areas (34).

$$
\begin{aligned}
V_{m i t} & =s v b_{m i} \quad \forall i \in S, \forall m \in T M, \quad t=1 \\
V_{m i t} & =V_{m i(t-1)}-\sum_{j \in W H} V U_{i j m(t-1)} \quad \forall i \in S, \forall m \in T M, \quad t=2 \\
V_{m i t} & =V_{m i(t-1)}-\sum_{j \in W H} V U_{i j m(t-1)} \\
& +\sum_{j \in W H} V U_{i j m\left(t-2 l t_{i j m}\right)} \quad \forall i \in S, \forall m \in T M, \forall t>2
\end{aligned}
$$$$
V_{m i t} \leq s v b_{m i} \quad \forall i \in S, \forall m \in T M, \forall t \in T I M
$$

$$
\begin{gathered}
\sum_{j=1}^{J} V U_{i j m t} \leq V_{m i t} \quad \forall i \in S, \forall m \in T M, \forall t \in T I M \\
V U_{i j m t} \leq q M O_{i j m t} \quad \forall i \in S, \forall j \in W H, \forall m \in T M, \forall t \in T I M \\
V E_{m j t}=w b v_{m j} \quad \forall j \in W H, \forall m \in T M, t=1 \\
V E_{m j t}=V E_{m j j(t-1)}-\sum_{k \in D A} V E U_{j k m(t-1)} \quad \forall j \in W H, \forall m \in T M, \quad t=2 \\
V E_{k j t}=V E_{m j(t-1)}-\sum_{k \in D A} V E U_{j k m(t-1)} \\
+\sum_{k \in D A} V E U_{j k m\left(t-2 l_{j k m}\right)} \quad \forall j \in W H, \forall m \in T M, \forall t>2 \\
V E_{m j t} \leq w b v_{m j} \quad \forall j \in W H, \forall m \in T M, \forall t \in T I M \\
\sum_{k=1}^{K} V U E_{j k m t} \leq V E_{m j t} \quad \forall j \in W H, \forall m \in T M, \forall t \in T I M \\
V U E_{j k m t} \leq q N_{j k m t} \\
\forall k \in D A, \forall j \in W H, \forall m \in T M, \forall t \in T I M .
\end{gathered}
$$

\section{Transportation Mode Assignment According to Vehicle Availabilities on Time Horizon}

35. Constraint Set (35) guarantees that a mode can be assigned to a route until all vehicles in the same transportation mode are used and if all vehicles in a mode are used. This mode cannot be assigned to a route until vehicles return to the supplier. Travel times from the supplier to the warehouse and the warehouse to the suppliers are assumed to be the same. Therefore, the waiting time to re-assign the same mode takes twice the vehicles' lead time of the route.

36. Constraint Set (36) works as Constraint Set (35) by cumulating over each supplier and terminal.

37. The total number of modes selected is limited by the total number of vehicles owned (37).

38. The total number of selected modes for a supplier can be at most the number of available vehicles (38).

39. Suppliers cannot select a mode unless a vehicle is used (39).

40. Constraint Set (40) works similarly to Constraint Set (35) for mode assignments from the terminals to the disaster areas.

41. Constraint Set (41) works similarly to Constraint Set (36) for mode assignments from the terminals to the disaster areas. 
42. Constraint Set (42) works similarly to Constraint Set (37) for mode assignments from the terminals to the disaster areas.

43. The total number of selected modes for a terminal can be at most the number of available vehicles (43).

44. Terminals cannot select a mode unless a vehicle is being used (44).
46. ULDs can only be loaded into suitable ITUs of a mode for the terminals (46).

$S U L D_{r c i j m t} \leq \operatorname{citu}_{r c m} q \quad \forall r \in U L D, \forall c \in I T U, \forall i \in S$, $\forall j \in W H, \forall m \in T M, \quad \forall t \in T I M$

$\sum_{j \in W H} \sum_{t^{\prime}=t}^{t^{\prime}+2 l t_{i j m}} M O_{i j m t^{\prime}} \leq q\left(V_{m i t}-\sum_{j \in W H} M O_{i j m t}\right) \quad \forall i \in S, \forall m \in T M, \forall t \in T I M$

$\sum_{j \in W H} \sum_{i \in S} \sum_{t^{\prime}=t}^{t^{\prime}+2 l t_{i j m}} M O_{i j m t^{\prime}} \leq q\left(\sum_{i \in S} V_{m i t}-\sum_{j \in W H} \sum_{i \in S} M O_{i j m t}\right) \quad \forall m \in T M, \forall t \in T I M$

$\sum_{j \in W H} \sum_{i \in S} M O_{i j m t} \leq \sum_{i \in S} s v b_{m i} \quad \forall m \in T M, \forall t \in T I M$

$\sum_{j=1}^{J} M O_{i j m t} \leq V_{m i t} \quad \forall i \in S, \forall m \in T M, \forall t \in T I M$

$M O_{i j m t} \leq V U_{i j m t} \quad \forall i \in S, \forall j \in W H, \forall m \in T M, \forall t \in T I M$

$\sum_{k \in D A} \sum_{t^{\prime}=t}^{t^{\prime}+2 l_{j k m}} N_{j k m t^{\prime}} \leq q\left(V E_{m j t}-\sum_{k \in D A} N_{j k m t}\right)$

$\forall j \in W H, \forall m \in T M, \forall t \in T I M$

$\sum_{j \in W H} \sum_{k \in D A} \sum_{t^{\prime}=t}^{t^{\prime}+2 l_{j k m}} N_{j k m t^{\prime}} \leq q\left(\sum_{j \in W H} V E_{m j t}-\sum_{k \in D A} \sum_{j \in W H} j \in W H\right)$

$\forall m \in T M, \forall t \in T I M$

$\sum_{j \in W H} \sum_{k \in D A} N_{j k m t} \leq \sum_{j \in W H} w b v_{m j} \quad \forall m \in T M, \forall t \in T I M$

$\sum_{j=1}^{J} N_{j k m t} \leq V E_{m j t} \quad \forall j \in W H, \forall m \in T M, \forall t \in T I M$

$N_{j k m t} \leq V U E_{j k m t} \quad \forall k \in D A, \forall j \in W H, \forall m \in T M, \forall t \in T I M$.

\section{ULD Assignment to ITU}

45. ULDs can only be loaded into suitable ITUs of a mode for suppliers (45).
$W U L D_{r c j k m t} \leq \operatorname{citu}_{r c m} q \quad \forall r \in U L D, \forall c \in I T U, \forall m$
$\in D A, \forall j \in W H, \forall k \in T M, \quad \forall t \in T I M$.

\section{Determine Intermodality}

47. Constraint Set (47) tracks the mode change during a particular period and the terminal using the arriving vehicle's mode (which departed a lead time ago) and the departing vehicle's mode.

48. If the same mode is used for the arriving and departing vehicles, Constraint Set (48) forces usage of the same ITUs.

$$
\begin{aligned}
& M O_{i j m t-l t_{i j m}}+N_{j k m^{\prime} t} \leq M C_{i j m m^{\prime} t}+1 \quad \forall i \in S, \\
& \forall j \in W H, \forall k \in D A, \forall m \in T M, m^{\prime} \in T M, \quad \forall t \in T I M
\end{aligned}
$$

$$
\begin{aligned}
& I T U S_{c i j m t-l t_{i j m}}+m c w_{m m^{\prime}} M C_{i j m m^{\prime} t} \\
& \quad \leq I T U W_{c j k m m^{\prime} t}+1 \quad \forall c \in I T U
\end{aligned}
$$

$\forall i \in S, \forall j \in W H, \forall k \in D A, \forall m \in T M$,

$\forall m^{\prime} \in T M, \forall t \in T I M$.

\section{Sign and Type Restrictions}

49. Non-negativity is imposed on integer decision variables (49).

50. A binary restriction is imposed on integer decision variables (50).

$$
\begin{aligned}
& S U L D_{r c i j k t}, W U L D_{r c j m k t}, S I T U_{c i j k t}, W I T U_{c j k m t}, X_{h i j m t}, Y_{h j k m t}, \\
& I N_{r j m t}, V_{m i t}, V E_{m j t}, V U_{i j m t}, V E U_{j k m t} \in \mathbb{Z}^{+}
\end{aligned}
$$

$$
M O_{i j m t}, N_{j k m t}, M C_{m m^{\prime} j t}, I T U S_{c i j m t}, I T U W_{j k m t}, W_{j t} \in\{0,1\}
$$


To measure the benefits of intermodal transportation, we define a Single-Mode Humanitarian Logistics Mathematical Model (SMM), which limits the intermodality of IMM by adding the following constraints:

\section{SMM Constraints}

51. If the arriving vehicle's mode (which departed a lead time ago) and the departing vehicle's mode is different, Constraint Set (51) ensures that the supplier and terminal cannot select those modes.

52. Only a single mode can be used by suppliers (52).

53. Only a single mode can be used by the terminals (53).

$$
\begin{aligned}
& M O_{i j m t-l l_{i j m}}+N_{j k m^{\prime} t} \leq q\left(1-M C_{i j m m^{\prime} t}\right) \\
& \quad \forall i \in S, \forall j \in W H, \forall m \neq m^{\prime}, m \text { and } \mathrm{m}^{\prime} \in T M, \forall t \in T I M
\end{aligned}
$$

$$
\sum_{m \in T M} M O_{i j m t} \leq 1 \quad \forall i \in S, \forall j \in W H, \forall t \in T I M
$$

$$
\sum_{m \in T M} N_{j k m t} \leq 1 \quad \forall j \in W H, \forall k \in D A, \forall t \in T I M
$$

In terms of complexity of the models, the number of variables and constraints is 13,657 and 12,743 for IMM and 13,657 and 14,807 for SMM, respectively.

\section{Experimental Study}

Van Wassenhove [6] classified disasters using two categories: (1) source (i.e., natural or human-made) and (2) occurrence duration (i.e., sudden onset or slow onset). In this paper and in our experimental study, we used data on natural and sudden disasters that have occurred previously in Turkey. The August 17, 1999 earthquake that occurred in the Marmara Region, the most industrialized region of Turkey, is a milestone for Turkey. As a result of this earthquake, 17,479 people died, 43,953 people were injured, and many lost their homes (Özmen [26]). The government and researchers focused more on investigating the possible ways to prevent İstanbul, the most crowded city of Turkey, from experiencing potential disasters (Parsons et al. [27]; Özdamar et al. [21]; Görmez et al. [28]).

We use the real-life data from Kavlak [29], from which four different disaster scenarios are generated, and we solved the SMM and IMM problem instances with our models. Comparing results, we identify the benefits of intermodal humanitarian transportation over single-mode transportation. We use five metrics for performance comparison, viz. total cost, number of total vehicles used $\left(U_{i j m t}\right.$ plus $\left.V E U_{j k m t}\right)$, capacity utilization of vehicles $\left(C U_{m i j t}\right)$, inventory amount $\left(I N_{r j t}\right)$, and number of total intermodal transportation units used $\left(S I T U_{\text {cijmt }}\right.$ plus WITU cjkmt ). Yadav and Barve [30] proposed twelve critical success factors (CSFs) to evaluate the performance of humanitarian supply chains. Two of them are inventory management and agile humanitarian supply chains (CSFs), where some of our metrics belong to those CSFs. Other than capacity utilization, the metrics are obvious by definition and they correspond to decision variables in the mathematical programming models. Capacity utilization of vehicles is defined in (54) as follows:

$$
\begin{aligned}
C U_{m i j t}= & 100 \frac{\sum_{c=1}^{C} \sum_{r=1}^{R} S U L D_{\text {rcijmt }} \text { leuld }_{r}}{\sum_{c=1}^{C} S I T U_{c i j m l} \text { leitu }_{c}} \\
& \forall m \in V H, \forall i \in S, \forall j \in W H, \forall t \in T I M .
\end{aligned}
$$

\subsection{Data and Parameter Estimation}

We used the following primary sources for data: DEMP, TCDD (State Railways of the Turkish Republic), Port (corresponding port operators in Turkey), DHL (the courier company), and expert opinion (Mediterranean Region sales manager of DHL Turkey). Appendix B gives the parameter, its source(s), and a short explanation of the data preparation process.

With the exception of $d e_{h k t}$, we believe Appendix B provides sufficient information on all parameters. Using the historical record on disasters from DEMP [31], we calculated the used item amounts per disaster victim for each relief item. Rounding these ratios to integers, we find that a group of five people needs one tent, five pillows, and ten blankets, which forms a shelter kit. Afterward, we use this shelter kit to generate total demand for disaster scenarios. In the next subsection, we explain how we distribute total demand to periods and obtain $d e_{h k t}$.

Table 3 City allocations of scenarios

\begin{tabular}{llll}
\hline Scenario \# & Suppliers & Terminals & Disaster areas \\
\hline 1 & Hamburg & İzmir & Denizli \\
& İstanbul & Antalya & \\
2 & Hamburg & İstanbul & Afyon \\
& Barcelona & İzmir & \\
3 & İzmir & Kayseri & Erzincan \\
& Adana & Kahramanmaraş & \\
4 & İstanbul & Samsun & Ankara \\
& Bursa & Eskişehir & \\
\hline
\end{tabular}


Fig. 4 Instance generation scheme

number of vehicle $\left(\sum_{i} \sum_{m} s v b_{m i}+\sum_{j} \sum_{m} w v b_{m j}\right)$

\subsection{Problem Instances}

We defined four scenarios using a number of cities for the supplier, terminal, and disaster area locations (see Table 3). The disaster areas were selected from cities where earthquakes had previously occurred.

Among these cities, there are logistic warehouses already established or under construction by the Turkish Disaster and Emergency Management Presidency (DEMP [32]). Moreover, there are Turkish State Railways logistic centers already established or under construction in a number of cities. (TCDD [33]).

For each of the four scenarios, we generated 21 instances and solved them using both SMM and IMM, which makes a total of 168 problem instances. Initial vehicle numbers determine the processing capacities of suppliers and terminals.
Therefore, to observe the flexibility of the mathematical model according to the proximity of the first demand occurrence for a given scenario, we use two levels for the initial number of available vehicles, viz. 92 and 412. For 92 vehicles, a demand density of 3 is used (i.e., demand occurs in three periods) that starts from period 4 (i.e., response time is 4) and have ten different interval distributions (0-9) on the time horizon. By interval distribution, we mean the number of periods without demand between consecutive demands. For 412 vehicles, we use demand densities of both 3 and 5 . For the demand density of 3 starting from period 16, we use four different interval distributions (0-3). For the demand density of 5, we assume both periods 4 and 16 for the starting periods, where we define five and two different interval distributions for those demand densities, respectively. Figure 4 summarizes the instance generation.

Fig. 5 Demand generation scheme

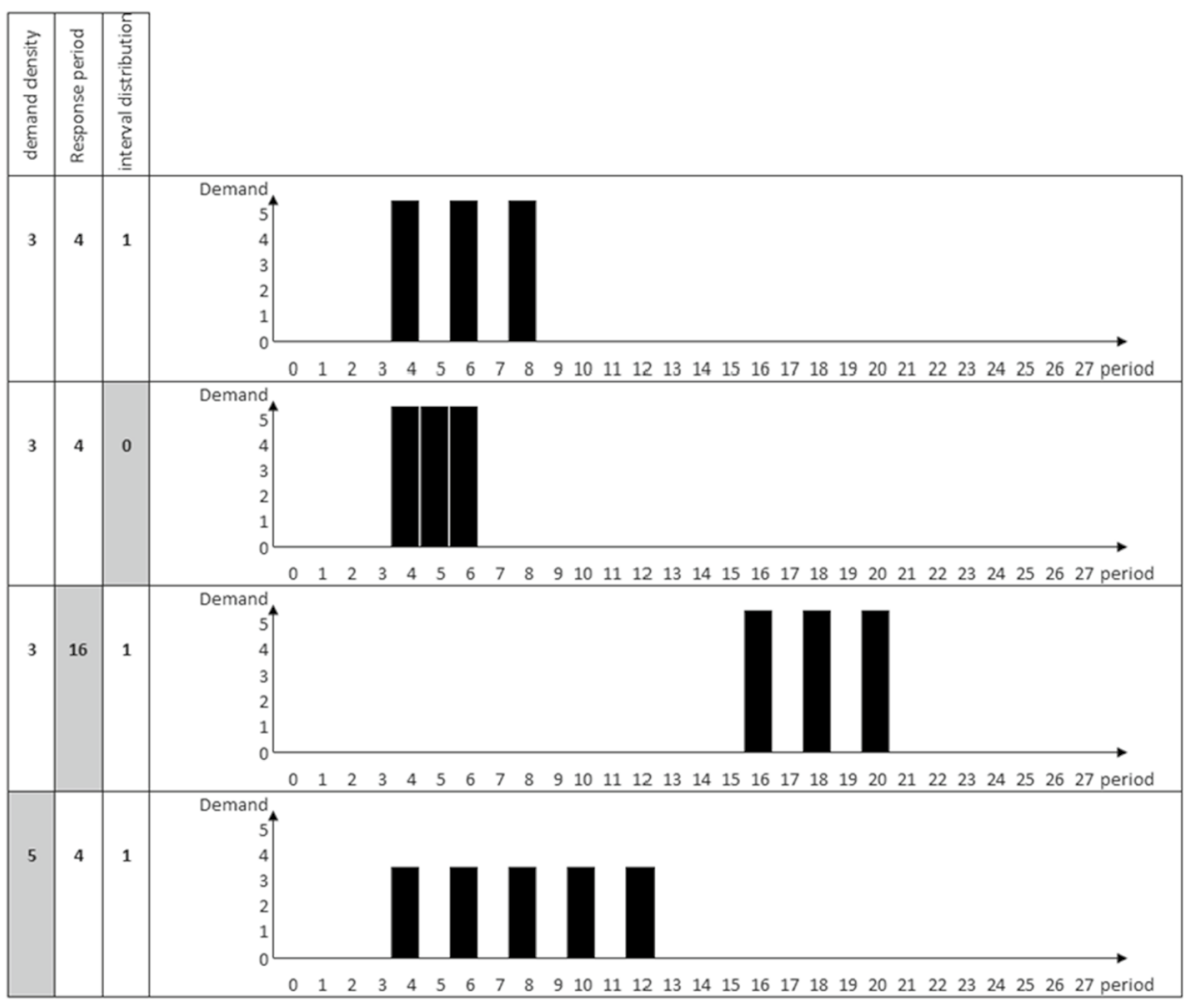


We explain the generation of total demand in the previous subsection and assume total demand is distributed equally over several periods of demand density. Figure 5 presents four examples to clarify our method.

In Fig. 5, the first scenario is the base where demand density is 3 , the response period 4 , and the interval distribution 1. When the interval distribution becomes 0 , demand occurs in consecutive periods. Compared to the base example, when the response period becomes 16 , the first demand occurrence is during period 16. Increasing demand density from 3 to 5 increases the number of periods that demand occurs, but at each demand occurrence, the amount is reduced such that the total demand is conserved.

Among all instances, we cannot find a feasible solution for the 18 instances of SMM of Scenario 2. When the vehicle number is the highest and demand starts in the latest period, we obtain feasible instances for high demand intervals (namely for 412 vehicles and demands starting in the 16th period with the demand density/interval pairs being $(3,2),(3,3)$, and $(5,1)$. The reason for this is that both suppliers are foreign and they cannot respond quickly.

\subsection{Numerical Results}

We performed all runs on a Windows 2012 Server workstation with 88 GB RAM and an Intel Xeon Processor E5-2620 using GAMS 24.0.2. Minimum, average, and maximum solution times of our models are 93.4, 135.5, and $186.3 \mathrm{~s}$, respectively.

For cost comparisons, we define the percentage increase in the objective function value (OFV) of SMM w.r.t. OFV of IMM in (55) as follows:

$G A P=\frac{O F V_{I M M}-O F V_{S M M}}{O F V_{S M M}} \times 100$

In Table 4, the numerical results are summarized w.r.t. the scenarios presented in Table 3. As explained in the previous subsection, only three instances for Scenario 2 could be solved.

Referring to Table 3, Scenarios 1 and 2 include international suppliers, in which the former scenario has one supplier and the latter both suppliers from abroad. We observe mode changing for only those two scenarios, and almost in all instances, mode changing occurs. For Scenarios 3 and 4, both suppliers are domestic, and mode changing does not exist, which leads to having the same objective function for SMM and IMM for all instances of the two scenarios, i.e., GAP is zero. Therefore, we can compare costs for all instances for Scenarios 1 and 2.

The average cost GAP is higher in Scenario 1, which indicates that the intermodality advantage is higher when

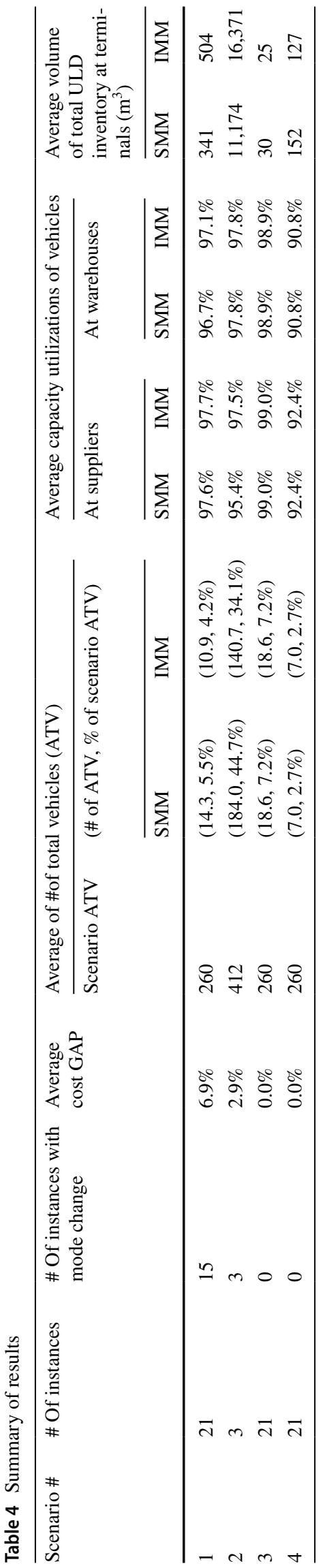




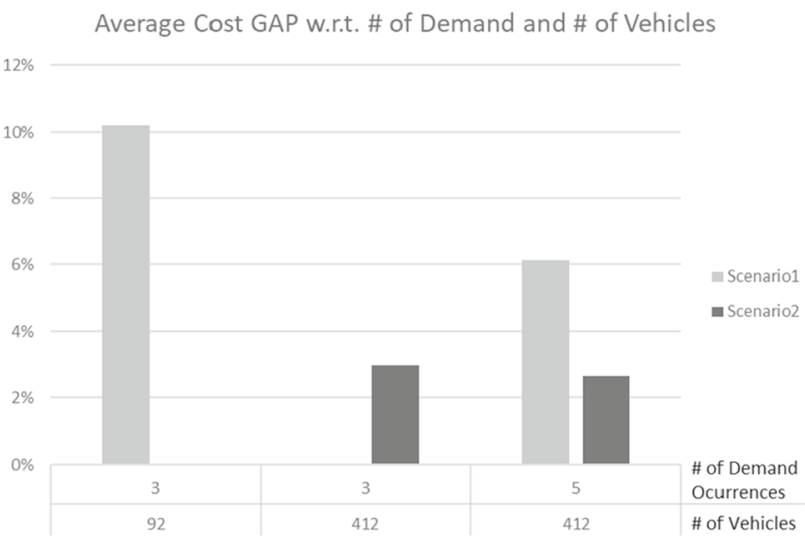

Fig. 6 Average cost gap with respect to the number of demand occurrences and number of vehicles

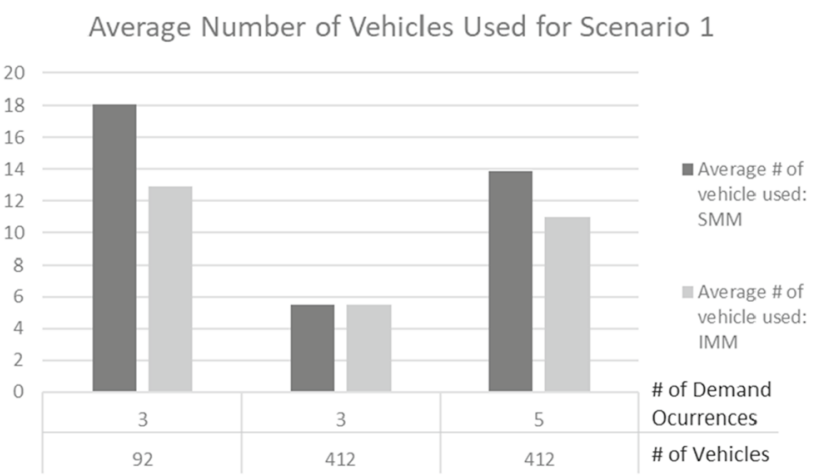

Fig. 7 Average number of vehicles used for Scenario 1

domestic and international supplier alternatives exist at the same time. More detailed analyses of GAP for Scenarios 1 and 2 can be seen in Fig. 6, which shows the average cost GAP w.r.t. the number of demands and the number of vehicles for the two scenarios. For the demand density and 412 vehicles, there is no GAP for Scenario 1 since SMM can solve for the same solution using more vehicles for less demand. GAP is not defined for Scenario 2 for a demand density of 3 and 92 vehicles since there is no feasible SMM solution. When there is a limited number of vehicles (92 vehicles), or there are more demand occurrences (such as demand density of 5 and 412 vehicles) for Scenario 1, there is a GAP. The largest GAP for a demand density of 3 and 92 vehicles in Scenario 1 is a $43.4 \%$ cost reduction w.r.t. SMM and it is for consecutive demand occurrences that start in the earliest period (i.e., shortest response time). Hence, in a short response time, using multi-mode transportation brings significant cost advantages by changing modes. For that specific instance, this finding is supported by changing modes twice for every three transshipments. For a demand density of 5 and 412 vehicles, and due to infeasibility issues, there is only one instance in Scenario 2, so it is not very meaningful to compare scenarios at this parameter setting.

We sum the number of vehicles used from suppliers to terminals and from terminals to the disaster area to find the total number of vehicles used in an instance. Since we use a different number of available vehicles among the instances for each scenario, we use the ratio of the average number of all vehicles used to the average number of available vehicles. From Table 4, similar to the GAP results, this percentage does not change from SMM to IMM for Scenarios 3 and 4. For Scenario 2, although the GAP was lower than Scenario 1, the reduction is more significant than Scenario 1. Thus, when all suppliers are international, disaster relief could be managed with a significantly lower number of vehicles, which is an essential operational advantage.

In all instances of Scenario 2, we do not observe significant differences in the percentage reduction, and therefore, we cannot distinguish the effects of the problem parameters on the metric. For further analysis, we compare the number of vehicles used for Scenario 1 in Fig. 7. As expected, the number of vehicles used is in line with cost. When there is a limited number of vehicles, or there are more demand occurrences, SMM uses more vehicles. The most considerable difference for vehicle usage is for the instance having the largest cost GAP, where 12 vehicles are used for IMM, whereas 19 are used for SMM.

Overall capacity utilization is more than $95 \%$, which is relatively high. Considering Table 4, for Scenarios 3 and 4, where the cost GAP is zero, we observe the same capacity utilization for SMM and IMM over both from the supplier to the warehouse and from the warehouse to the disaster area. For Scenarios 1 and 2, we observe that capacity utilization is lower (or at most equal) in SMM due to mode restriction in general. For some instances, mode restriction has a counter effect, and by changing to a transportation mode that has lower cost per capacity, it may result in lower capacity utilization for IMM. On average, the differences in capacity utilization are small.

We calculate the total volume of the ULD inventory at the terminals using the volumes and the ULD-1 and ULD-2 inventory amounts. We observe from Table 4 that when there is at least one international supplier, IMM tends to hold more ULD inventory at the terminals. When the two suppliers are domestic, the behavior is the opposite. Specifically, in Scenario 2, the average amount of inventory held is significantly larger than the other scenarios for both SMM and IMM, since both suppliers are foreign, and they are far from the disaster area. In contrast, IMM holds almost 50\% more inventory than SMM. The reason for holding more inventory in IMM is due to using only the rail mode from the warehouse to the disaster area to benefit from unit capacity transportation cost. Rail capacity in ULD is large, and train departures are less frequent, which results in holding more 
inventory at the warehouse. In terms of composition, $79 \%$ of inventory is the ULD-2 type for SMM, whereas it is $87 \%$ for IMM. ULD-2 is larger and better to hold inventory, which affects the composition of ULD-2 in total inventory.

For the last metric, i.e., the number of ITUs used, among all instances, there are only three instances where the number of ITUs used differs between SMM and IMM. The common property among those three instances is the number of vehicles being the highest and response time being the latest. SMM uses more ITUs than IMM since after selecting a mode on a route, it should continue with the same mode, where switching to another mode might be more efficient.

\section{An Extension of the Model}

\subsection{Problem Description of the Extended Model}

Flexibility is defined as "a multi-dimensional ability to adapt efficiently to changing external and internal conditions in disasters to maintain or improve humanitarian supply chain performance (Baharmand et al. [34])." As an extension of our mathematical model, we added a limited relief supply as a changing external condition and relaxed the demand fulfillment constraint (Assumption \#15). We also added relief item procurement cost and backorder (deprivation) cost to our objective function. We aim to provide our mathematical model flexibility of not meeting demands and penalizing unmet demands with deprivation cost. We used the deprivation cost function provided by Holguin-Veras et al. [9] and calculated exponentially increasing period level deprivation costs. We assumed that all demand actually originated at the time of disaster and penalized deprivation cost w.r.t. time zero.

Resilience is defined as "the ability of a system to return to its original state or move to a new, more desirable state after being disturbed (Christopher and Beck [35])." For instance, the original state of the transportation network might include only highway transportation, but after being disrupted by a collapsed bridge as a result of an earthquake, the new state might consist of only air and rail modes. Thus, to include resilience in our discussions, we use different network availability levels for each problem instance. Since the network is disrupted by the disaster, we only consider the path (i.e., arc) availabilities connected to the location of the disaster. If any path to a disaster area is disrupted, we assume it occurs at the time of the disaster (i.e., time zero) and continues over the entire planning horizon. For the three transportation modes, we make further assumptions. If the maritime mode becomes unavailable, it is due to damage to the harbor, which means all the paths from all warehouses are disrupted. For ground mode, the highway connections from warehouses to the disaster location are separate, and therefore, any path closure from a particular warehouse does not affect the others. Railway connections are also considered similarly. For the air mode, helicopters and other aircraft can be used. Helicopters are not affected by disasters since they can land almost anywhere, so for helicopters, path availability is not affected by disasters. Assuming that all aircraft use the same single airport at the disaster location, these paths are either all open or all closed for aircraft depending on availability.

To measure resilience, we use the beta index of network connectivity (i.e., availability), which is the total number of paths divided by the total number of nodes (Rodrigue [36]). It is evident that as the same number of nodes in the network is connected by multiple transportation modes, the beta index increases because of the increased number of available paths. Therefore, a higher beta index is desired for a network to be resilient.

\subsection{Extended Mathematical Models}

To extend our mathematical models, we add the following decision variable for unmet demand and cost parameters:

$U_{h k t}=$ Amount of unmet (backordered) demand for item $h$ at disaster area $k$ at the end of time $t$

$c u_{h t}=$ Cost of unmet demand (i.e., deprivation cost)

for item $h$ for one period at time $t$

$p c_{h t}=$ Procurement cost of item $h$ at time $t$

Adding (56) to the objective function (1), we include unmet demand penalty and procurement cost to the model.

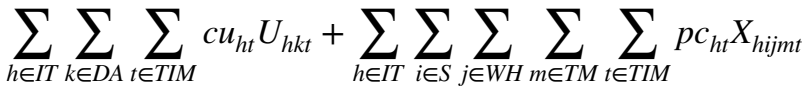

In order to relax the assumption of no unmet demand, we replace (2) with (57) and (58).

$$
\begin{aligned}
& \sum_{m=1}^{M} \sum_{j=1}^{J} Y_{h j k m\left(t-l_{j k m}\right)}+U_{h k t} \geq d e_{h k t} \quad \forall h \in I T, \forall k \in D A, t=1 \\
& \sum_{m=1}^{M} \sum_{j=1}^{J} Y_{h j k m\left(t-l_{j k m}\right)}+U_{h k t}-U_{h k t-1} \geq d e_{h k t} \\
& \forall h \in I T, \forall k \in D A, \forall t>1 \text { and } \in T I M
\end{aligned}
$$

From (57), relief item demand of each disaster area in the first periods is either satisfied or left to the second period as unmet demand. 
By (58), relief item demand of each disaster area in a period and the accumulated unmet demand is either satisfied or left to the next period as unmet demand.

We develop extended IMM (IMM-Ext) and extended SMM (SMM-Ext) by applying these modifications to IMM and SMM, respectively. The number of variables and constraints is 13,705 and 12,751 for IMM-Ext and 13,705 and 14,815 for SMM-Ext.

\subsection{Additional Data and Parameter Estimation for the Extended Model}

We gathered data for procurement and deprivation costs of two relief items: tents and blankets. Procurement cost is obtained from the State Supply Office online sales platform (SSO [37] and SSO [19]). Deprivation cost (i.e., cost of unmet and backordered demand) starts from the 20th hour after the disaster. We used the exponential cost function given by Holguin-Veras et al. [9]:

$\gamma(t)=0.2869 e^{0.0998 t}$

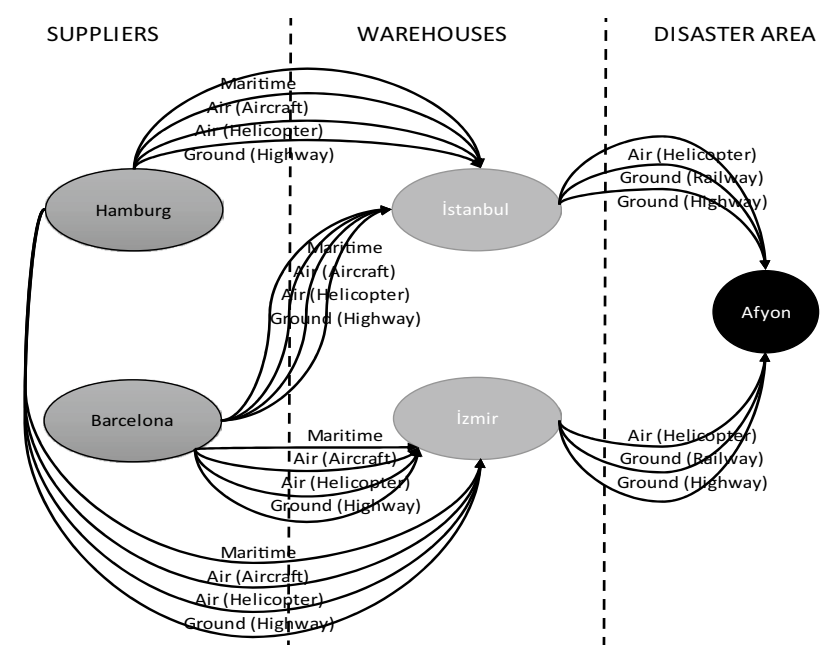

where $t$ is the number of hours that passed after the disaster. The deprivation cost of the 20th hour is taken as equal to the original procurement cost of the relief item using the corrected deprivation cost function in Holguin-Veras et al. [9], with the cost increasing as time passes. To give an idea about the magnitude of the deprivation cost, the following estimations can be provided: $72 \mathrm{~h}$. after a disaster, the deprivation cost is about $8 \%$ more than the procurement cost; $96 \mathrm{~h}$. after a disaster, the deprivation cost is almost twice the procurement cost; and $120 \mathrm{~h}$. after a disaster, deprivation cost is more than ten times the procurement cost. Hence, deprivation cost becomes more significant when beneficiaries suffer for longer time periods.

\subsection{Numerical Results of the Extended Model}

As explained in Subsection 5.2, we were able to find a feasible solution for only three instances (out of 21) of SMM for Scenario 2 since both suppliers are international. The infeasibility of SMM instances stemmed from demand satisfaction constraints. In the extended model, we relaxed the demand satisfaction constraint and allowed for unmet demand. Therefore, we would use Scenario 2 for the numerical studies of our extended model. In Fig. 8, the network availability of Scenario 2 is given. Between any node, there can be five path types for three transportation modes (maritime, air-aircraft, air-helicopter, ground-highway, and ground-railway). For Scenario 2, ground railway is not available between suppliers and warehouses, and maritime and air-aircraft are not available between warehouses and the disaster area.

We calculate the beta index considering the entire network. As an example, we can consider that no path is disrupted because of the disaster and all paths are open. Then, the beta index is calculated. There are a total of 16 paths from the suppliers to warehouses and 6 paths from the warehouses to the disaster area, which gives a total of 22 available paths for the entire network. Dividing this total by the total number of nodes ( 2 suppliers, 2 warehouses, and 1

Fig. 8 Network availability of Scenario 2

Table 5 Network availability levels and beta index values for intermodal transportation for Scenario 2

\begin{tabular}{|c|c|c|c|c|c|c|c|c|c|c|c|c|c|c|c|c|c|c|}
\hline \multicolumn{3}{|l|}{ Path } & \multicolumn{16}{|c|}{ Network availability level } \\
\hline From & To & Mode & A1 & A2 & A3 & A4 & A5 & A6 & A7 & A8 & A9 & A10 & A11 & A12 & A13 & A14 & A15 & A16 \\
\hline İstanbul & Afyon & Ground (highway) & 1 & 1 & 1 & 1 & 1 & 1 & 1 & 1 & 0 & 0 & 0 & 0 & 0 & 0 & 0 & 0 \\
\hline İstanbul & Afyon & Ground (railway) & 1 & 1 & 1 & 1 & 0 & 0 & 0 & 0 & 1 & 1 & 1 & 1 & 0 & 0 & 0 & 0 \\
\hline İstanbul & Afyon & Air (helicopter) & 1 & 1 & 1 & 1 & 1 & 1 & 1 & 1 & 1 & 1 & 1 & 1 & 1 & 1 & 1 & 1 \\
\hline İzmir & Afyon & Ground (highway) & 1 & 1 & 0 & 0 & 1 & 1 & 0 & 0 & 1 & 1 & 0 & 0 & 1 & 1 & 0 & 0 \\
\hline İzmir & Afyon & Ground (railway) & 1 & 0 & 1 & 0 & 1 & 0 & 1 & 0 & 1 & 0 & 1 & 0 & 1 & 0 & 1 & 0 \\
\hline İzmir & Afyon & Air (helicopter) & 1 & 1 & 1 & 1 & 1 & 1 & 1 & 1 & 1 & 1 & 1 & 1 & 1 & 1 & 1 & 1 \\
\hline Beta Index & & & 4.4 & 4.2 & 4.2 & 4.0 & 4.2 & 4.0 & 4.0 & 3.8 & 4.2 & 4.0 & 4.0 & 3.8 & 4.0 & 3.8 & 3.8 & 3.6 \\
\hline
\end{tabular}


Table 6 Summary of results for extended models

\begin{tabular}{lllll}
\hline $\begin{array}{l}\text { Total \# of } \\
\text { vehicles (TV) }\end{array}$ & Model & $\begin{array}{l}\text { Average of unmet demand cost } \\
\text { (AUDC), in thousand TRY }\end{array}$ & $\begin{array}{l}\text { Average of total cost } \\
\text { (ATC), in thousand TRY }\end{array}$ & \% AUDC of ATC \\
\hline 92 & IMM-Ext & 469,232 & 517,961 & $90.3 \%$ \\
412 & SMM-Ext & 475,152 & 524,095 & $90.4 \%$ \\
& IMM-Ext & 45,346 & 75,158 & $45.1 \%$ \\
& SMM-Ext & 54,399 & 85,333 & $48.1 \%$ \\
\hline
\end{tabular}

Fig. 9 Average total cost of IMM-Ext and SMM-Ext w.r.t. Beta Index

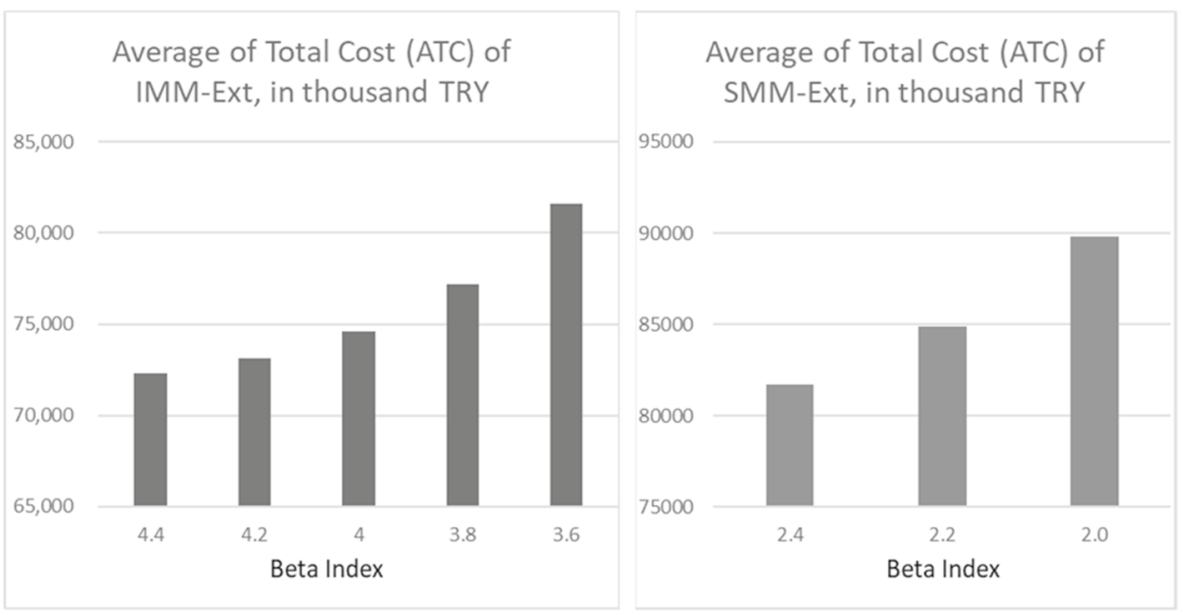

a) IMM-Ext b) SMM-Ext disaster area, summing to 5), the beta index for this instance is found as $4.4(=22 / 5)$.

Considering all the path disruption possibilities, we enumerate all 16 different path availabilities and define them as network availability levels in Table 5 for Scenario 2 for intermodal transportation. Note that level A1 corresponds to the above example. For each level, we calculate the beta index for intermodal transportation.

For single-mode transportation, since a mode cannot be changed at the warehouse, if a mode is unavailable from a supplier to a warehouse, we exclude the same mode from the warehouse to the disaster area and calculate the beta index correspondingly. Considering the same example of the A1 level, maritime and air-aircraft modes from suppliers to the warehouses are not counted since they are not available from the warehouses to the disaster area. Similarly, ground railway is not counted since it is only available from the warehouses to the disaster area. Therefore, a total of 12 paths is available and the beta index for A1 for single mode is found to be $2.4(=12 / 5)$. Note that only four availability levels remain for the single mode. For example, A1, A2, A5, and A6 correspond to the same availability level for the single mode.

We consider the same vehicle availability, demand density, response period, and interval distribution levels given in Fig. 4 and generate 42 settings for Scenario 2. With 16
Table 7 Summary of results for extended models

\begin{tabular}{lll}
\hline $\begin{array}{l}\text { Total \# of vehicles } \\
(\mathrm{TV})\end{array}$ & Model & $\begin{array}{l}\text { Average volume of total } \\
\text { ULD inventory at terminals } \\
\left(\mathrm{m}^{3}\right)\end{array}$ \\
\hline 92 & IMM-Ext & 1656 \\
& SMM-Ext & 2307 \\
412 & IMM-Ext & 3816 \\
& SMM-Ext & 8356 \\
\hline
\end{tabular}

different network availability levels and two transportation types (intermodal and single mode), we solved a total of 1344 problem instances. We performed all runs at a Windows 2012 Server workstation with 88 GB RAM and an Intel Xeon Processor E5-2620 using GAMS 24.0.2. The minimum, average, and maximum solution times of our models are 83.1, 755.4, and 14,149.0 s, respectively.

As presented in Table 6, IMM-Ext gives less average total cost, average unmet cost, and percent average unmet cost over the average total cost compared to SMM-Ext and this difference is larger when vehicle availability level is 412 . The reason for this is the number of available vehicles affecting the overall transportation capacity with larger capacity 
Average Volume of Total ULD Inventory at Terminals (m3)

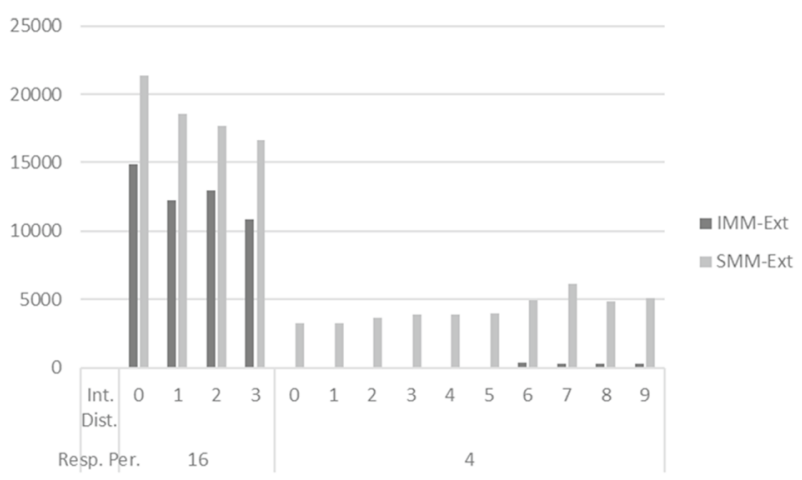

Fig. 10 Average volume of total ULD Inventory at terminals (m3) of IMM-Ext and SMM-Ext w.r.t. interval distribution and response periods

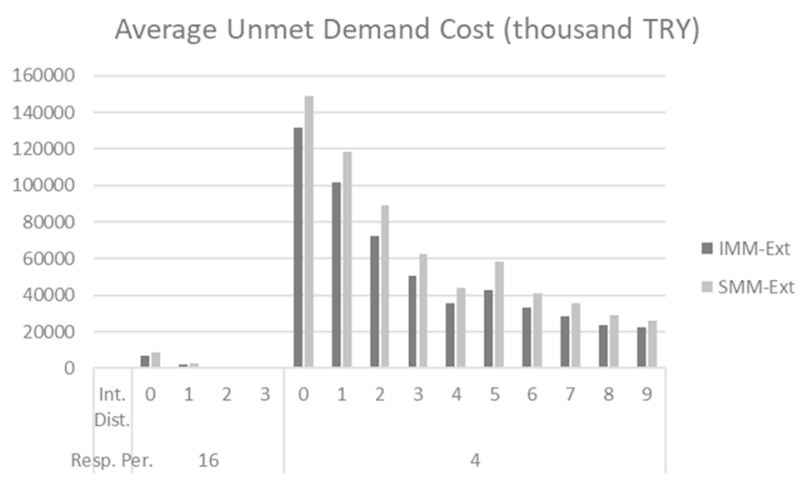

Fig. 11 Average unmet demand cost (thousand TRY) of IMM-Ext and SMM-Ext w.r.t. interval distribution and response periods

allowing intermodal transportation to operate more effectively. Lower unmet demand cost indicates that intermodal transportation is more flexible than single-mode transportation and it better satisfies the demand when a network is disrupted.

For the 412 available vehicles case, with decreasing beta index, i.e., a less resilient network, average total cost increases for both IMM-Ext and SMM-Ext (Fig. 9a, $\mathrm{b}$, respectively). This indicates that increased network resilience has a positive effect on the performance of both options.

Average ULD inventory volumes are given in Table 7. More available vehicles allow the holding of more inventory in the warehouses for both IMM-Ext and SMM-Ext. IMMExt holds less inventory than SMM-Ext for both levels.

For the 412 available vehicles case, IMM-Ext holds less inventory compared to SMM-Ext for any interval distribution of demand and response period (Fig. 10). Realizing demand earlier (i.e., response period is 4) allows holding less inventory than late demand realization (i.e., response period is 16) for both models. For late demand realization, both models tend to hold more inventory to reduce unmet demand.

Average unmet demand costs of IMM-Ext and SMMExt w.r.t. interval distribution and response periods are given in Fig. 11. From the unmet demand cost perspective, both models have average unmet demand costs close to zero for the response period of 16 , which is a result in line with inventory volumes. Moreover, IMM-Ext has less cost compared to SMM-Ext for any case.

\section{Conclusions}

This study addresses intermodal freight transportation (IFT) in humanitarian logistics for transportation of relief items during the response phase of a disaster. To the best of our knowledge, this is the first study in the literature presenting IFT modeling in humanitarian logistics using loading units. The contributions of this study can be listed as follows: (1) Two suitable unit load devices are proposed for humanitarian logistics; (2) a mathematical model which includes integer variable representation for vehicle fleets on different transportation modes is developed; and (3) intermodal transportation is compared with singlemode transportation using a real-life dataset.

This study is novel because capacitated intermodal transport units (ITU) and unit load devices (ULD) are explicitly considered for the first time in the literature to properly represent intermodal transportation. Moreover, parking limitations (e.g., the container capacity of a warehouse) and holding costs are included with integer vehicle flow representations. To account for flexibility and resilience of intermodal freight transportation, an extended model is presented with deprivation cost (i.e., backorder cost of unmet demands) and varying route availabilities.

We review both the commercial logistics and humanitarian logistics literature and analyze the use of multiple transportation modes. Since intermodal transportation requires an intermodal transport unit (e.g., a container), we propose unit load devices using standard dimensions from commercial air cargo transportation. The proposed integer programming model is based on a time-space network by considering route and vehicle availabilities that change over time. We represent the number of vehicles available in each period with integer variables, which is an improvement on the previous related models. Hence, the number of decision variables decreases, making the model more tractable. To see the potential benefits of IFT in humanitarian logistics, we compare our proposed IFT model with a single-mode transportation model via four different scenarios. We used total cost, the number of vehicles used, capacity utilization of vehicles, and inventory amount as performance metrics. 
The first and the second scenarios are where suppliers are international NGOs, and the third and the fourth scenarios are where suppliers are national. Demand density, response times, interval distribution of demand on time horizon, and the number of vehicles initially available are altered in these scenarios.

We observe that using IFT provides maximum benefit (i.e., $43 \%$ improvement in the objective function) when demand is in consecutive periods, requires the shortest response time, and the number of vehicles is low. Another observation we make is that IFT changes transportation mode in two out of three transshipments. Therefore, we can claim that when an immediate response is required and demand is in consecutive periods, using IFT brings cost advantages, thereby overcoming the disadvantage of changing modes. The number of vehicles used follows a similar pattern to cost such that IFT uses fewer vehicles when an immediate response is required and demand is in consecutive periods. We observe that capacity utilization is as high as $95 \%$ on average with low variability. Therefore, the capacity utilization metric appears to be insignificant for intermodality. Inventory is held more in IFT when international NGOs are involved, and less inventory is held in IFT when a national response is required. IFT benefits are also visible in the extended model results. Changing network availability highlighted the flexibility and resilience of IFT.

Based on our results, we have three policy suggestions. We observe that the number of vehicles available is the most critical parameter in cost performance. Organizations coping with disaster relief should ensure adequate amounts of vehicle parking. Secondly, using suppliers solely far from disaster areas increases inventory significantly. Policymakers are better to use suppliers that are as close as possible to disaster areas. Finally, intermodality brings flexibility for immediate response. Therefore, policymakers should consider intermodality in their planning; i.e., they should choose suppliers and warehouse locations in network designs and procure any necessary equipment for intermodal transportation, such as unit load devices.

For future work, this study can be enhanced in several ways. We use five network nodes with two echelons for each scenario; moreover, more complex supply chain configurations may be tested in the future. The beta index of more complex network configurations will be more diverse when single-mode and multiple-mode alternatives are compared. When the network includes a greater number of nodes and paths, the mathematical model will lend itself to large-scale instances for which a heuristic algorithm can be developed.

Future studies might also increase the number and level of factors in the experimental design. Some factors that might be considered could include periods, number of suppliers, warehouses, disaster areas, type of ITUs, types of ULDs, and types of relief items. Other objective functions which can be considered in the future are minimization of response times and maximizing road reliability. When other objective functions are tested, a multi-criterion mathematical model could be developed with varying importance of different objective functions.

During the response phase of humanitarian logistics, the transportation of relief items plays a vital role in survival. Hence, an efficient transportation plan should be developed rapidly. This study is the first step to create a resilient transportation plan which includes mode changes with vehicle and route availabilities. Our perspective of combining intermodal freight transportation and humanitarian logistics using unit load devices is novel to disaster operations management practice and research.

\section{Appendix A: Parameters Used in the Mathematical Model}

\subsection{Sets}

ITSet of relief items, $\mathrm{IT}=\{1, \ldots, \mathrm{H}\}$

SSet of supplier nodes, $\mathrm{S}=\{1, \ldots, \mathrm{I}\}$

WHSet of terminal nodes, $\mathrm{WH}=\{1, \ldots, \mathrm{J}\}$

DASet of disaster areas, $\mathrm{DA}=\{1, \ldots, \mathrm{K}\}$

TMSet of transportation modes, $\mathrm{TM}=\{1, \ldots, \mathrm{M}\}$

TIMSet of time periods, $\operatorname{TIM}=\{1, \ldots, \mathrm{T}\}$

ITUSet of intermodal transportation unit types,

$\mathrm{ITU}=\{1, \ldots, \mathrm{C}\}$

ULDSet of unit load device type, $\operatorname{ULD}=\{1, \ldots, \mathrm{R}\}$

\subsection{Parameters}

$d e_{h k t}=$ Demand of item $h$ in disaster area $k$ at time $t$

ing $_{h r}=$ Number of item $h$ in ULD $r$

$c w i t u_{j}=$ ITU capacity of terminal $j$

cwuld $_{j}=$ ULD capacity of terminal $j$

citu $_{r c m}=$ Loading availability of ULD $r$ into ITU

$c$ in transportation mode $m$

$c a_{c m}=$ ITU $c$ capacity of vehicle in transportation mode $m$

$s v b_{m i}=$ Number of available vehicles in transportation mode $m$ of supplier

$i$ at the beginning of period $t=1$ 
$w v b_{m j}=$ Number of available vehicles in transportation mode

$m$ of terminal $j$ at the beginning of period $t=1$

vuld $_{r}=$ Volume of ULD $r$

$v_{i t u}=$ Volume of ITU $c$

weuld $_{r}=$ Weight of ULD $r$

weitu $_{c}=$ Weight of ITU $c$

leuld $_{r}=$ Length of ULD $r$

leitu $_{c}=$ Length of ITU $c$

$c_{\text {rijm }}=$ Cost of transporting one kilogram of ULD $r$ from supplier $i$ to terminal $j$ by using transportation mode $m$

$c o_{r j k m}=$ Cost of transporting one kilogram of ULD $r$ from terminal $j$ to disaster area $k$ by using transportation mode $m$

$c c_{c i j m}=$ Cost of transporting an ITU $c$ from supplier $i$ to terminal $j$ by using transportation mode $m$

$c c o_{c j k m}=$ Cost of transporting an ITU $c$ from terminal $j$ to disaster area $k$ by using transportation mode $m$

$h o_{r j t}=$ Inventory holding cost of ULD $r$ in terminal $j$ at time $t$

$\operatorname{bein}_{r j}=$ Inventory of ULD $r$ in terminal $j$ at beginning $t=1$

$a_{i j m t}=$ Availability of route from supplier $i$ to terminal $j$ for transportation mode $m$ at time $t$

$a v_{j k m t}=$ Availability of route from terminal $j$ to disaster area $k$ for transportation mode $m$ at time $t$

$l t_{i j m}=$ Needed time to transport items from supplier $i$ to terminal $j$ by transportation mode $m$

$l_{j k m}=$ Needed time to transport items from terminal $j$ to disaster areas $k$ by transportation mode $m$

$m c c_{j m m \prime}=$ Cost of mode changing between transportation modes $m$ and $m^{\prime}$ in terminal $j$

$m c w_{m m^{\prime}}= \begin{cases}1, & \text { if arriving mode } m \text { is same with departure mode } m^{\prime} \text { at terminal } \\ 0, & \text { otherwise }\end{cases}$ 


\begin{tabular}{|c|c|c|c|}
\hline Parameter & Source & References & Explanation \\
\hline$d e_{h k t}$ & Generated & DEMP [31] & $\begin{array}{l}\text { Demand gener- } \\
\text { ated from real } \\
\text { earthquakes } \\
\text { hard-hit house } \\
\text { data }\end{array}$ \\
\hline ing $_{h r}$ & Calculated & $\begin{array}{l}\text { Turkish } \\
\text { Airlines [38] } \\
\text { and Brinkley } \\
\text { [39] }\end{array}$ & $\begin{array}{l}\text { Calculated using } \\
\text { standard ULD } \\
\text { dimensions } \\
\text { and relief item } \\
\text { dimensions }\end{array}$ \\
\hline cwitu $_{j}$, cwuld $_{j}$ & Calculated & $\begin{array}{l}\text { Seagoline [40], } \\
\text { ASBAS [41], } \\
\text { Kumport } \\
\text { [42], TCDD } \\
\text { [33], Sam- } \\
\text { sunport [43] } \\
\text { and Gemport } \\
\text { [13] }\end{array}$ & $\begin{array}{l}\text { Calculated using } \\
\text { ITU and ULD } \\
\text { dimensions } \\
\text { and terminal } \\
\text { sizes }\end{array}$ \\
\hline$c i t u_{r c m}$ & Calculated & $\begin{array}{l}\text { Turkish } \\
\text { Airlines [38] } \\
\text { and Brinkley } \\
\text { [39] }\end{array}$ & $\begin{array}{l}\text { Calculated using } \\
\text { ITU, ULD } \\
\text { dimensions, } \\
\text { transportation } \\
\text { mode capabili- } \\
\text { ties }\end{array}$ \\
\hline$c a_{c m}$ & Web & $\begin{array}{l}\text { Nasmaritime } \\
\text { [44] }\end{array}$ & $\begin{array}{l}\text { Vehicle capaci- } \\
\text { ties are taken } \\
\text { from the } \\
\text { web pages of } \\
\text { related organi- } \\
\text { zations }\end{array}$ \\
\hline $\begin{array}{l}\text { vuld }_{r}, \text { vitu }_{c} \text {, } \\
\quad \text { weuld }_{r}, \text { leuld }_{r}\end{array}$ & Web & $\begin{array}{l}\text { Turkish } \\
\text { Airlines [38] } \\
\text { and Brinkley } \\
\text { [39] }\end{array}$ & $\begin{array}{l}\text { ULD dimen- } \\
\text { sions, volumes } \\
\text { and weights } \\
\text { information on } \\
\text { web pages }\end{array}$ \\
\hline weitu $_{c}$, leitu $_{c}$ & Web & $\begin{array}{l}\text { Turkish } \\
\text { Airlines [38] } \\
\text { and Brinkley } \\
\text { [39] }\end{array}$ & $\begin{array}{l}\text { Container } \\
\text { dimensions } \\
\text { are taken from } \\
\text { related web } \\
\text { sites }\end{array}$ \\
\hline$c_{r i j m}, c o_{r j k m}$ & Web & $\begin{array}{c}\text { Turkish Air- } \\
\text { lines [45] }\end{array}$ & $\begin{array}{l}\text { ULD transporta- } \\
\text { tion costs are } \\
\text { obtained from } \\
\text { the Turkish } \\
\text { Airlines air } \\
\text { freight price } \\
\text { list }\end{array}$ \\
\hline
\end{tabular}

\begin{tabular}{|c|c|c|c|}
\hline Parameter & Source & References & Explanation \\
\hline$c c_{c i j m}, c c o_{c j k m}$ & $\begin{array}{l}\text { Expert Opin- } \\
\text { ion, TCDD }\end{array}$ & $\begin{array}{c}\text { Tekin [46] and } \\
\text { TCDD [47] }\end{array}$ & $\begin{array}{l}\text { Transportation } \\
\text { costs of ITUs } \\
\text { in seaway, } \\
\text { highway, and } \\
\text { airway modes } \\
\text { are determined } \\
\text { from DHL and } \\
\text { domestic and } \\
\text { foreign price } \\
\text { tariffs. For } \\
\text { railway mode, } \\
\text { TCDD cargo } \\
\text { tariffs are used } \\
\text { for domestic } \\
\text { railway trans- } \\
\text { portation }\end{array}$ \\
\hline$h o_{r j t}$ & TCDD, Ports & $\begin{array}{l}\text { Seagoline [48], } \\
\text { ASBAS [41], } \\
\text { Kumport } \\
\text { [42], TCDD } \\
\text { [49], Sam- } \\
\text { sunport [43], } \\
\text { Gemport [13] }\end{array}$ & $\begin{array}{l}\text { Holding costs } \\
\text { are determined } \\
\text { by using price } \\
\text { tariffs accord- } \\
\text { ing to the cities } \\
\text { of shipping } \\
\text { companies and } \\
\text { TCDD }\end{array}$ \\
\hline$a_{i j m t}, a v_{j k m t}$ & Calculated & $\begin{array}{l}\text { Tekin [46], } \\
\text { TCDD [47] } \\
\text { and Turkish } \\
\text { Airlines [38] }\end{array}$ & $\begin{array}{l}0 \text { or } 1 \text { is } \\
\text { assigned } \\
\text { depending on } \\
\text { terminal avail- } \\
\text { ability }\end{array}$ \\
\hline$l t_{i j m}, l_{j k m}$ & Calculated & $\begin{array}{l}\text { Tekin [46], } \\
\text { TCDD [47] } \\
\text { and Turkish } \\
\text { Airlines [38] }\end{array}$ & $\begin{array}{l}\text { Calculated } \\
\text { using distance } \\
\text { information } \\
\text { obtained from } \\
\text { DHL, TCDD, } \\
\text { and Turkish } \\
\text { Airlines web- } \\
\text { pages }\end{array}$ \\
\hline $\begin{array}{c}m c c_{j m m}, f c i t u_{c}, \\
f c i h l, f c v_{m}\end{array}$ & Calculated & $\begin{array}{l}\text { Mersinport } \\
{[50]}\end{array}$ & $\begin{array}{l}\text { Calculated using } \\
\text { Ports price lists }\end{array}$ \\
\hline
\end{tabular}

Acknowledgements We would like to thank the Editor and the anonymous Reviewers for their constructive comments and suggestions for improvement. We are grateful to the Scientific and Technological Research Council of Turkey (TUBITAK) for partially financing this work under the 3501 Career Development Program Grant \#113M493. We owe special thanks to the logistics company professionals who provided real-life data. This research would not be possible without these contributions.

Funding This work was partially supported by the Scientific and Technological Research Council of Turkey (TUBITAK) under Grant \#113M493.

\section{References}

1. CRED (2021). https://www.emdat.be/explanatory-notes. Accessed 04 Feb 2021

2. UNDRR. https://www.undrr.org/media/48008/download. Accessed 05 Feb 2021 (2020) 
3. Altay, N.; Green, W.G.; III.: OR/MS research in disaster operations management. Eur. J. Oper. Res. 175(1), 475-493 (2006)

4. Kopczak, L.R.; Thomas, A.S.: From Logistics to Supply Chain Management: The Path Forward in the Humanitarian Sector. Fritz Institute, California (2005)

5. Özkapıcı, D.B.; Ertem, M.A.; Aygüneş, H.: Intermodal humanitarian logistics model based on maritime transportation in Istanbul. Nat. Hazards 83(1), 345-364 (2016)

6. Van Wassenhove, L.N.: Humanitarian aid logistics: supply chain management in high gear. J. Oper. Res. Soc. 57(5), 475-489 (2006)

7. Adams, T.M.; Bekkem, K.R.; Toledo-Durán, E.J.: Freight resilience measures. J. Transp. Eng. 138(11), 1403-1409 (2012)

8. Ponomarov, S.Y.; Holcomb, M.C.: Understanding the concept of supply chain resilience. Int. J. Logist. Manag. 20(1), 124-143 (2009)

9. Holguín-Veras, J.; Amaya-Leal, J.; Cantillo, V.; Van Wassenhove, L.N.; Aros-Vera, F.; Jaller, M.: Econometric estimation of deprivation cost functions: a contingent valuation experiment. J. Oper. Manag. 45, 44-56 (2016)

10. Holguín-Veras, J.; Pérez, N.; Jaller, M.; Van Wassenhove, L.N.; Aros-Vera, F.: On the appropriate objective function for postdisaster humanitarian logistics models. J. Oper. Manag. 31(5), 262-280 (2013)

11. UNESCAP. Manual on Modernization of Inland Water Transport for Integration within a Multimodal Transport System Chapter 1. http://www.unescap.org/resources/manual-moder nization-inland-water-transport-integration-within-multimodaltransport-system. Accessed 05 Jan 2016 (2016)

12. Ertem, M.A.; İşbilir, M.; Arslan, A.Ş: Review of intermodal freight transportation in humanitarian logistics. Eur. Transp. Res. Rev. 9(1), 10 (2017)

13. Gemport. http://www.gemport.com.tr/sayfalar.asp?pageID= TarifeHesapla. Accessed 05 Jan 2016

14. Balçık, B.; Beamon, B.M.; Krejci, C.C.; Muramatsu, K.M.; Ramirez, M.: Coordination in humanitarian relief chains: practices, challenges and opportunities. Int. J. Prod. Econ. 126(1), 22-34 (2010)

15. IFRC (2016). What is a Disaster?. https://www.ifrc.org/en/whatwe-do/disaster-management/about-disasters/what-is-a-disaster/. Accessed 05 Jan 2016

16. EMDAT (2016). The EM-DAT glossary. http://www.emdat.be/ glossary/9. Accessed 05 Jan 2016

17. IATA (2016). Unit load devices (ULD). https://www.iata.org/ whatwedo/cargo/unit-load-devices/pages/index.aspx. Accessed 05 Jan 2016

18. Özdamar, L.; Ertem, M.A.: Models, solutions and enabling technologies in humanitarian logistics. Eur. J. Oper. Res. 244(1), 55-65 (2015)

19. Tavana, M.; Abtahi, A.R.; Di Caprio, D.; Hashemi, R.; YousefiZenouz, R.: An integrated location-inventory-routing humanitarian supply chain network with pre-and post-disaster management considerations. Socio-Econ Plan. Sci. 64, 21-37 (2018)

20. Haghani, A.; Oh, S.C.: Formulation and solution of a multicommodity, multimodal network flow model for disaster relief operations. Transp. Res A-Pol 30(3), 231-250 (1996)

21. Özdamar, L.; Ekinci, E.; Küçükyazici, B.: Emergency logistics planning in natural disasters. Ann. Oper. Res. 129(1-4), 217-245 (2004)

22. Clark, A.; Culkin, B.: A network transshipment model for planning humanitarian relief operations after a natural disaster. In: Decision Aid Models for Disaster Management and Emergencies, Atlantis Press, pp. 233-257 (2013)

23. Vaillancourt, A.: Kit management in humanitarian supply chains. Int. J. Disast. Risk RE 18, 64-71 (2016)
24. Baskaya, S.; Ertem, M.A.; Duran, S.: Pre-positioning of relief items in humanitarian logistics considering lateral transshipment opportunities. Socioecon. Plann. Sci. 57, 50-60 (2017)

25. Balçık, B.; Beamon, B.M.; Smilowitz, K.: Last mile distribution in humanitarian relief. J. Intell. Transp. Syst. 12(2), 51-63 (2008)

26. Özmen, B.: Ağustos 1999 İzmit Körfezi Depreminin Hasar Durumu (Rakamsal Verilerle). Türkiye Deprem Vakfı, vo. 132 (2017)

27. Parsons, T.; Toda, S.; Stein, R.S.; Barka, A.; Dieterich, J.H.: Heightened odds of large earthquakes near Istanbul: an interaction-based probability calculation. Science 288(5466), 661-665 (2000)

28. Görmez, N.; Köksalan, M.; Salman, F.S.: Locating disaster response facilities in Istanbul. J. Oper. Res. Soc. 62(7), 1239-1252 (2011)

29. Kavlak, H.: Intermodal freight transportation in humanitarian logistics. Thesis, Çankaya University, Ankara, Turkey M.Sc (2016)

30. Yadav, D.K.; Barve, A.: Analysis of critical success factors of humanitarian supply chain: an application of interpretive structural modeling. Int. J. Disast. Risk Re 12, 213-225 (2015)

31. DEMP. https://www.tabb-analiz.afad.gov.tr. Accessed 05 Jan 2016

32. DEMP. https://www.afad.gov.tr/UserFiles/File/Haber_ic_Foto/ lojistik_depolar.pdf. Accessed 05 Jan 2016

33. TCDD. http://www.tcdd.gov.tr/lojistik-merkezler+m129. Accessed 05 Jan 2016

34. Baharmand, H.; Comes, T.; Lauras, M.: Defining and measuring the network flexibility of humanitarian supply chains: insights from the $2015 \mathrm{Nepal}$ earthquake. Ann. Oper. Res. 283, 961-1000 (2019)

35. Christopher, M.; Peck, H.: Building the resilient supply chain. Int. J. Logist. Manag. 15(2), 1-14 (2004)

36. Rodrigue, J.P.: The Geography of Transport Systems, Vol. 5. Routledge, New York (2020)

37. SSO (2021b). https://www.dmo.gov.tr/Katalog/Urun/Detay/ 558222_15980. Accessed 05 Feb 2021

38. Turkish Airlines. http://www.turkishcargo.com.tr/tr/hizmet-agive-filo/uld. Accessed 05 Jan 2016

39. Brinkley [11]. http://www.brinkley.cc/ULD/akh.htm. Accessed 05 Jan 2016

40. Seagoline. http://www.seagoline.com/local-offices/turkey-turkish/ freetime-demurrage-detention/ardiye-free-sure-ve-tarife-bilgileri/. Accessed 05 Jan 2016

41. ASBAS. http://www.asbas.com.tr/asbas_antalya_serbest_bolge si-tarifeler.asp. Accessed 05 Jan 2016

42. Kumport. http://www.kumport.com.tr/hizmet_tarife_konteyner. html. Accessed 05 Jan 2016

43. Samsunport (2016). http://www.samsunport.com.tr/pdf/tarife.pdf. Accessed 05 Jan 2016

44. Nasmaritime. http://www.nasmaritime.com/kitap/kontgem-15112 010-snas.pdf. Accessed 05 Jan 2016

45. Turkish Airlines. http://www.turkishcargo.com.tr/tr/e-kargo/ kargo-ucretleri. Accessed 05 Jan 2016

46. Tekin, Ş.C.: Personal Communication. Sales Manager of DHL Turkey Mediterranean Region (2016)

47. TCDD. https://portal1.tcdd.gov.tr/tcdd(bD10ciZjPTEwMCZ $\mathrm{kPW} 1 \mathrm{pbg}==) / \mathrm{zy} 02 / \mathrm{yuk}$ tasima_fiyatlari?menuId=https://porta 11.tcdd.gov.tr/tcdd(bD10ciZjPTEwMCZkPW1pbg==)/zy02/yuk_ tasima_fiyatlari. Accessed 05 Jan 2016

48. SSO (2021a). https://www.dmo.gov.tr/Katalog/Urun/Detay/ 742937_915416. Accessed 05 Jan 2021

49. TCDD. http://www.tcdd.gov.tr/files/yuk/tarife.pdf. Accessed 05Jan 2016

50. Mersinport. http://www.mersinport.com.tr/images/pdf/tarife.pdf. Accessed 05 Jan 2016 
51. Abdelgawad, H.; Abdulhai, B.: Emergency evacuation planning as a network design problem: a critical review. Transp. Lett. 1(1), 41-58 (2009)

52. Adıvar, B.; Mert, A.: International disaster relief planning with fuzzy credibility. Fuzzy Optim. Decis. Mak 9(4), 413-433 (2010)

53. Barbarosoğlu, G.; Arda, Y.: A two-stage stochastic programming framework for transportation planning in disaster response. J. Oper. Res. Soc. 55(1), 43-53 (2004)

54. Haghani, A.; Oh, S.C.: Testing and evaluation of a multi-commodity multimodal network flow model for disaster relief management. J. Adv. Transp. 31(3), 249-282 (1997)

55. Hu, Z.H.: A container multimodal transportation scheduling approach based on immune affinity model for emergency relief. Expert Syst. Appl. 38(3), 2632-2639 (2011)
56. Salmerón, J.; Apte, A.: Stochastic optimisation for natural disaster asset prepositioning. Prod. Oper. Manag. 19(5), 561-574 (2010)

57. Tean, E.S.: Optimised positioning of pre-disaster relief force and assets. Doctoral dissertation, Monterey, California. Naval Postgraduate School (2006)

58. Vitoriano, B.; Ortuno, T.; Tirado, G.: HADS, a goal programming-based humanitarian aid distribution system. J. Multicriteria Decis. Anal. 16(1-2), 55-64 (2009)

59. Yi, W.; Kumar, A.: Ant colony optimisation for disaster relief operations. Transp. Re E-Log 43(6), 660-672 (2007)

60. Zhu, J.; Huang, J.; Liu, D.; Han, J.: Resources allocation problem for local reserve depots in disaster management based on scenario analysis. In: 7th International Symposium on Operations Research and its Applications. Lijiang, China, pp. 395-407 (2008) 